\title{
Projected 21st Century Sea-Level Changes, Observed Sea Level Extremes, and Sea Level Allowances for Norway
}

\author{
Matthew J. R. Simpson ${ }^{1, *}$, Oda R. Ravndal ${ }^{2}$, Hilde Sande ${ }^{2}$, Jan Even Ø. Nilsen ${ }^{3}$ (D), \\ Halfdan P. Kierulf ${ }^{1}$, Olav Vestøl ${ }^{1}$ and Holger Steffen ${ }^{4}$ \\ 1 Geodetic Institute, Norwegian Mapping Authority, 3507 Hønefoss, Norway; \\ halfdan.kierulf@kartverket.no (H.P.K.); olav.vestol@kartverket.no (O.V.) \\ 2 Hydrographic Service, Norwegian Mapping Authority, Professor Olav Hanssens vei 10, 4021 Stavanger, \\ Norway; oda.ravndal@kartverket.no (O.R.R.); hilde.sande.borck@kartverket.no (H.S.) \\ 3 Nansen Environmental and Remote Sensing Center, and Bjerknes Centre for Climate Research, \\ Thormøhlensgt. 47, 5006 Bergen, Norway; even@nersc.no \\ 4 Lantmäteriet, Lantmäterigatan 2C, 80182 Gävle, Sweden; holger.steffen@lm.se \\ * Correspondence: matthew.simpson@kartverket.no; Tel.: +47-3211-8306
}

Received: 31 May 2017; Accepted: 18 July 2017; Published: 14 August 2017

\begin{abstract}
Changes to mean sea level and/or sea level extremes (e.g., storm surges) will lead to changes in coastal impacts. These changes represent a changing exposure or risk to our society. Here, we present 21st century sea-level projections for Norway largely based on the Fifth Assessment Report from the Intergovernmental Panel for Climate Change (IPCC AR5). An important component of past and present sea-level change in Norway is glacial isostatic adjustment. We therefore pay special attention to vertical land motion, which is constrained using new geodetic observations with improved spatial coverage and accuracies, and modelling work. Projected ensemble mean 21st century relative sea-level changes for Norway are, depending on location, from -0.10 to $0.30 \mathrm{~m}$ for emission scenario RCP2.6; 0.00 to $0.35 \mathrm{~m}$ for RCP 4.5 ; and 0.15 to $0.55 \mathrm{~m}$ for RCP8.5. For all RCPs, the projected ensemble mean indicates that the vast majority of the Norwegian coast will experience a rise in sea level. Norway's official return heights for extreme sea levels are estimated using the average conditional exceedance rate (ACER) method. We adapt an approach for calculating sea level allowances for use with the ACER method. All the allowances calculated give values above the projected ensemble mean Relative Sea Level (RSL) rise, i.e., to preserve the likelihood of flooding from extreme sea levels, a height increase above the most likely RSL rise should be used in planning. We also show that the likelihood of exceeding present-day return heights will dramatically increase with sea-level rise.
\end{abstract}

Keywords: Norway; sea-level change; regional sea-level projections; IPCC AR5; glacial isostatic adjustment; extreme sea levels; ACER extreme value prediction; sea level allowances; tide gauges

\section{Introduction}

In the global setting, Norway is commonly perceived as being at low risk from sea-level rise. The coastline is largely characterized by steep topography and exposed bedrock that is resistant to erosion. In addition to this, the land surface is experiencing on-going uplift due to the loss of the large ice sheet that once covered Fennoscandia (a process known as glacial isostatic adjustment, GIA; e.g., [1,2]). It is well recognized that this uplift process will act to mitigate future sea-level rise (e.g., [3]). These factors suggest that, in comparison to other coastal countries, Norway has a generally low physical vulnerability to increasing sea levels [4]. 
There are, nevertheless, several reasons for wanting to gain a better understanding of future sea-level changes and their associated risks. Firstly, while the general perception that Norway is at low risk from sea-level rise is broadly true, it is not the case in certain parts of the country and on local scales. In trying to understand this issue, one can start by briefly considering the nature of the Norwegian landscape, which has been shaped over numerous glaciations. The coastline is long, rugged and complicated, with an estimated 240,000 islands. There are large areas of steep exposed bedrock but also some low-lying areas of continuous and soft sediment deposits (mostly glacial till). The majority of Norway's cities and numerous towns and villages are situated along the coast and, in recent years, many large developments have been undertaken close to the shoreline. There is also an extensive infrastructure of bridges, tunnels and ports connecting these communities. Previous vulnerability assessments have helped identify the low-lying coastal areas of Norway that are at risk from sea-level rise owing to their important cultural and economic value $[4,5]$. These studies have shown that, in some specific areas where economic activities are concentrated close to the coast (e.g., oil, fishing and shipping industries), the impacts of sea-level rise could be significant.

Secondly, there is a clear need to take into account our changing climate in planning and/or adaption policy. Here it is the job of researchers to provide up-to-date scientific information on sea level to help decision makers. In our view, this information should be updated at least as often as the Intergovernmental Panel for Climate Change (IPCC) publishes its assessment reports, which is every 6 to 7 years (IPCC AR5 was released in 2013). Providing such information means setting up a framework for how to apply sea-level projections on a local scale. It also requires close cooperation of the institutions involved in different aspects of sea level science (no single institution has overall responsibility for sea level science in Norway). Once we have reviewed and updated our scientific understanding of sea level, then a decision can be made on how that information is used in policy. On that point, we note that although advice on sea-level rise is normally taken into account in planning, sea level is not specifically addressed in national legislation (i.e., Norway's building code) [4,5].

Relative Sea Level (RSL) change is defined as the change in ocean surface height with respect to the solid Earth. Paleo observations from across Fennoscandia, including Norway, show a spatial pattern of RSL change over the past $\sim 10,000$ years that largely reflects vertical land uplift due to GIA (e.g., [6]). Norway has therefore experienced an overall fall in RSL as the solid Earth surface has rebounded, in some places as much as several hundred meters. As well as being evident in the paleo record, analyses of the Norwegian tide-gauge network (Figure 1) also show that GIA is an important component of twentieth century RSL change (e.g., [7-10]). These tide-gauge data, which are unevenly spaced along the coast, indicate that over the past 100 years some areas of Norway underwent a RSL fall while other areas underwent a limited RSL rise (that is, values somewhat below the global mean rise). In parts of the country where RSL is rising, climate driven sea-level rise is now greater than land uplift. This represents a reversal of the general trend of late-Holocene relative sea-level fall.

To be able to quantify the effect of sea-level change on flood risk assessments, information on future sea levels is required in a probabilistic form (i.e., for a specific future date, an assessment is made of the probability or likelihood of a certain sea level occurring). Up until relatively recently, such projections for mean sea-level changes were not achievable. The assessment made by Church et al. [11] in IPCC AR5 was that confidence in projecting sea-level changes had improved due to: (1) our improved understanding of observed and modelled 20th century global sea-level changes (e.g., [12]); and (2) progress made with quantifying ice-dynamic contributions (e.g., [13]). This has meant that probabilistic projections are now possible, but there remain significant challenges to overcome before projections of sea-level change can be considered truly robust. In IPCC AR5, future global sea-level rise is assessed as likely $(p>66 \%)$ to be within the range of the projections [11]. Partly owing to insufficient and inconsistent evidence, however, the IPCC AR5 authors refrained from trying to quantify the probability of levels above the likely range (i.e., the upper tail of the probability distribution that essentially relates to the poorly constrained future behaviour of the ice sheets). The same main authors also reached the same conclusion in a more recent review [14]. 
Not having information on the complete probability distribution of the sea-level projections presents a problem for their use in practical applications. Understanding of low probability but potentially large impact future sea-level changes is important for coastal management [15]. Furthermore, knowledge (or an assumption) about the complete probability distribution of future sea-level rise is also required for calculating sea level "allowances" [16,17], a possible attractive option in coastal planning for Norway. Allowances give the height by which an asset needs to be raised so that the probability of flooding remains preserved for an uncertain future sea-level change [16,17]. As IPCC AR5 did not provide information beyond the likely ranges, some studies have instead made use of expert elicitations to help quantify the complete probability distribution of future sea-level rise (e.g., $[18,19])$. At the same time, post IPCC AR5, there have also been advances in our understanding of present and future ice sheet changes. Most notably, observations of glacier losses in Antarctica suggest the early stages of a collapse may have begun (e.g., [20,21]). Recent modelling studies of Antarctica have tried to quantify how such a marine collapse might contribute to future sea-level rise from the continent with diverging results (e.g., [22,23]). The amounts and timing of these potential future contributions from Antarctica are very uncertain. What is apparent, however, is that this area of sea level science is rapidly evolving.

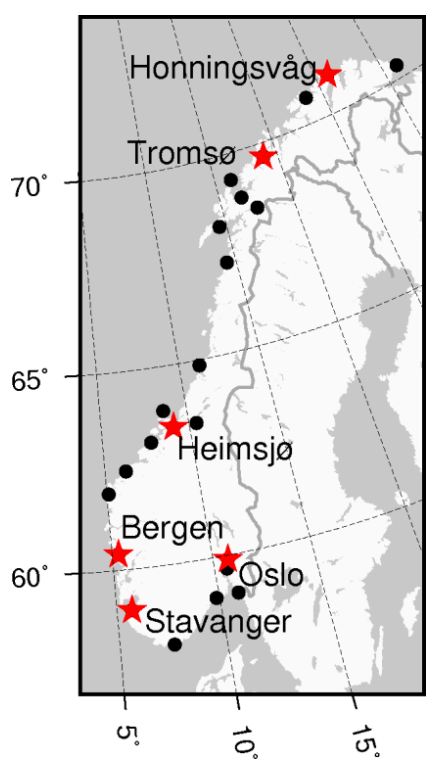

Figure 1. The 23 tide gauges that form the Norwegian tide gauge network. The red stars with names indicate the tide gauge sites chosen as key locations in this article (i.e., here we show sea-level projections and return periods for extreme sea levels).

This article is structured as follows. We begin by examining vertical land motion (VLM) in Norway, an important component of present sea-level change in Scandinavia, which we constrain using new Global Positioning System (GPS) measurements and modelling [2]. The VLM solution is a key component used in the sea-level projections presented here. Our regional projections of 21st century sea-level changes for Norway are largely based on findings from IPCC AR5 and Coupled Model Intercomparison Project phase 5 (CMIP5) output [24]. The main aim of the work is to show sea-level projections for Norway updated with IPCC AR5 science. We go on to look at how our sea-level projections can be combined with statistics on extreme sea levels. Here we use the Average conditional exceedance rate (ACER) method for estimating the return periods for extreme sea levels. This is the approach used for calculating the official return periods for Norway [25]. We then adapt a method for calculating sea level allowances $[16,17]$ for use with our preferred ACER return heights. Finally, allowances are calculated for the Norwegian coast using different normal distributions of future sea-level rise. 


\section{Materials and Methods}

\subsection{Present-Day Vertical Land Motion in Norway}

There is a long history of GIA research in Fennoscandia [26]. A wide variety of observations are available for the study of GIA, for example, paleo sea level, tide gauge, levelling and terrestrial gravity measurements. Now, over the past two decades, the satellite based observation systems of GPS and the Gravity Recovery and Climate Experiment (GRACE) have provided new insights into the process of GIA (see Steffen and Wu [27], for a review of all the datasets).

Such observations of GIA in Fennoscandia have traditionally been used to infer details of Earth's viscosity structure and/or the region's ice history (e.g., [1,6,28,29]). They also inform us on vertical land motion-an important component of present-day RSL change for Norway. The development of GPS, in particular, has enabled us to image crustal deformation to a high degree of precision. These observations show that present-day VLM across Fennoscandia is dominated by the on-going relaxation of the Earth in response to past ice mass loss (e.g., [1]). While the broad pattern of land motion in Norway reflects GIA, a number of other physical processes can also cause vertical movements, for example, tectonics, elastic loading effects, sediment deposition or compaction, or groundwater storage changes. Generally speaking these processes are thought to be small in Norway but they can be significant in some areas and especially on local scales (e.g., [30]).

Here we make use of new GPS observations and GIA modelling work (Kierulf et al. [2]), and updated precise levelling measurements. The new results are employed to determine vertical land motion, with corresponding uncertainties, for the Norwegian coast. We also show gravitational effects on sea level associated with GIA. These changes in the gravity field are largely driven by the movement of mantle material from the forebulge areas peripheral to Fennoscandia back towards the center as the region uplifts. The movement of mantle mass acts to increase gravitational attraction which, in turn, causes sea surface heights to increase. Such gravitational changes in Fennoscandia have been observed using both satellite gravity data from GRACE and ground-based gravity measurements (e.g., [31]). Previous work has shown, based on empirical derivation, that where the vertical rates are around $10 \mathrm{~mm} /$ year at the centre of uplift in Fennoscandia the corresponding geoid change is $0.6 \mathrm{~mm} /$ year (i.e., the sea surface height change is $\sim 6 \%$ of the land uplift signal) [32,33].

Our findings are compared to the GIA solution applied in IPCC AR5, which is based on a combination of the ICE-5G [34] and ANU-ICE models (Lambeck et al. [6] and subsequent improvements).

\subsubsection{Permanent GPS and Levelling Networks and Analysis}

The establishment of permanent GPS networks in the Nordic countries (Norway, Sweden, Finland, and Denmark) began in the early 1990s. A dense network exists in the region today, which is primarily used for real-time positioning and navigation, but also geodynamic and geophysical studies (Figure 2). Many GIA-related GPS investigations have been completed under the Baseline Inferences for Fennoscandian Rebound Observations, Sea level, and Tectonics (BIFROST) project [35]. Crustal deformation rates from the BIFROST network have been published regularly [1,35-38], largely incorporating Swedish and Finnish stations and also some Norwegian and North European (e.g., Germany, Poland, and Estonia) stations.

The Norwegian GPS network is currently comprised of 160 permanent stations. As the network has been gradually built up over a number of years, some GPS sites have longer time series than others. This has implications for the reliability of the crustal velocities estimated from GPS observations in different parts of the network. In the first analysis of the entire Norwegian network, Kierulf et al. [39] examined the relationship between time series length and the accuracy of the velocity estimates. The authors suggested that only vertical velocities estimated from more than 3 years of data can be considered reliable. Using this 3-year cut-off and data up until the beginning of 2011, Kierulf et al. [39] were able to determine vertical velocities for $65(\sim 40 \%)$ of the 160 GPS stations in the network. In 
the more recent study of Kierulf et al. [2], where they use data up until the beginning of 2013 (i.e., 2 more years of data), the authors were able to determine vertical velocities estimates for $92(\sim 60 \%)$ of the 160 GPS stations in the network (Figure 2a). Thus, velocities presented in Kierulf et al. [2] and used in this study have a better spatial coverage than before and, owing to longer time series, improved accuracies.

In their analysis Kierulf et al. [2] employ the GAMIT/GLOBK software [40] to derive daily solutions for GPS stations across the Nordic countries. The velocities presented here are realized in the ITRF2008 reference frame [41]. Note that a recent review concluded that the ITRF is stable along each axis to better than $0.5 \mathrm{~mm}$ /year and has a scale error of less $0.3 \mathrm{~mm} /$ year [42]. For more information on the analysis strategy, see Kierulf et al. [2]. Note that 4 GPS stations, Tregde, Tjøme, Moldjord and Mysen, are removed from further analysis in this work as subsequent inspection of the data suggests they may be unstable.
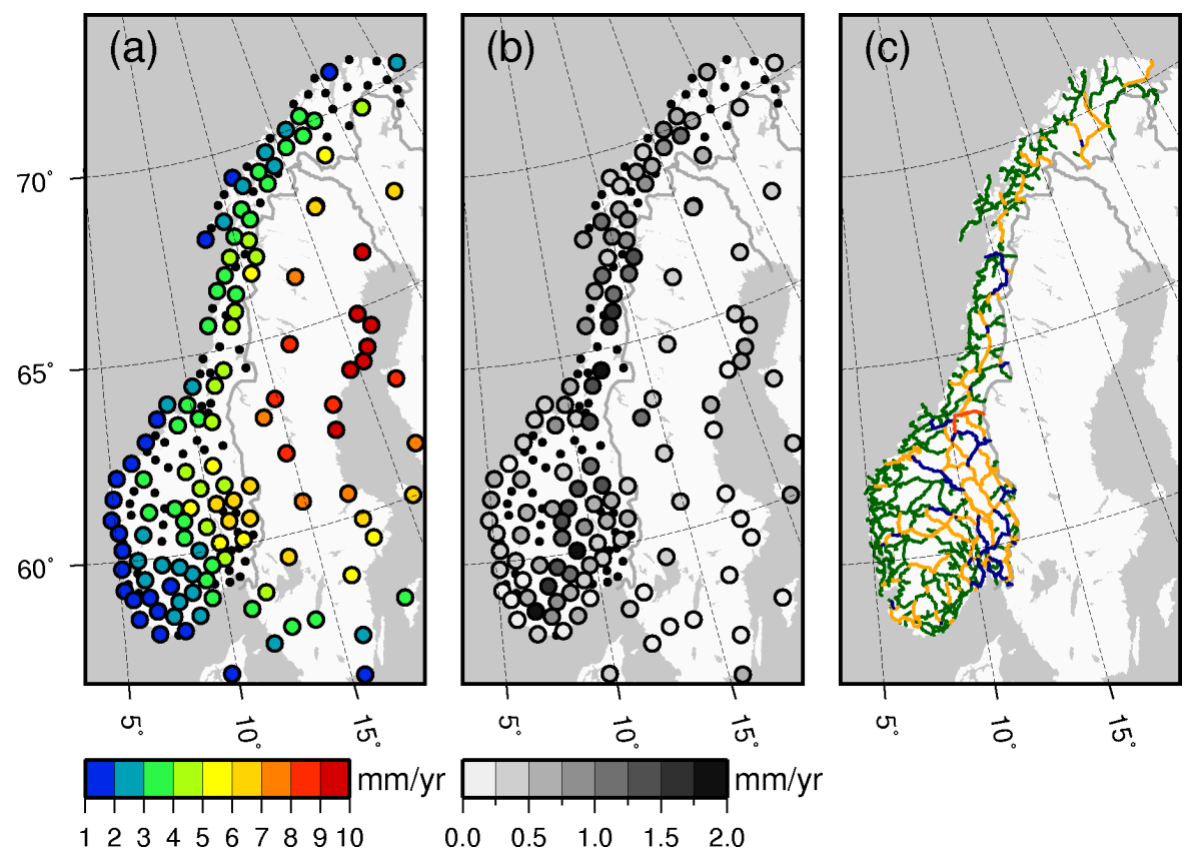

Figure 2. (a) Observed vertical land motion from the GPS measurements: black dots mark stations with less than three years of data, which are not included in this study as they are considered unreliable; (b) uncertainty on the observations (standard error); and (c) the levelling lines used. Red lines have been measured four times, orange lines three times, blue lines two times and green lines once. Levelling data from outside of Norway are included in our least-squares collocation solution (see below) but are not shown here.

In addition to the GPS stations which observe crustal motion in a geodetic reference frame, we also make use of repeated precise levelling data which provide a measure of relative land movements. The levelling data help us to better constrain VLM and are of particular use in areas between the GPS stations. The Norwegian levelling data have been collected over several years and date from 1916 to present. Levelling lines in Norway, including the number of times they have been measured, are shown in Figure 2c.

\subsubsection{Defining a Vertical Velocity Field for Norway}

The GPS observations indicate that vertical land motion over Norway varies between 1 and $7 \mathrm{~mm}$ /year. Coastal locations generally have uplift rates lower than $5 \mathrm{~mm}$ /year (Figure 2a). The average minimum distance between the 92 Norwegian GPS stations for which we have velocities is 
$57 \mathrm{~km}$. Thus, we consider the spatial coverage of the observations to be good, but there are coastal areas in the middle and in northern Norway where we currently lack crustal velocity estimates.

Figure $2 \mathrm{~b}$ shows the standard errors on the observations. The GPS stations in coastal areas in the middle of Norway have higher uncertainties than elsewhere. These stations have generally shorter time series and consequently larger uncertainties. The average uncertainty on the 92 velocity estimates in Norway is $\pm 0.75 \mathrm{~mm}$ /year (standard error). We explore two different approaches to defining a continuous vertical crustal velocity field, with corresponding uncertainties, using (1) results from GIA modelling and (2) applying least-squares collocation to the levelling and GPS observations (see Vestøl [33] for details of the methodology). The GIA model is briefly described below.

\subsubsection{Glacial Isostatic Adjustment Modelling}

A GIA model is generally composed of three components: a model of grounded past ice evolution (for Fennoscandia and other ice covered areas), a sea level model to compute the redistribution of ocean mass for a given ice and Earth model, and an Earth model to compute the solid Earth deformation associated with the ice-ocean loading history. Note that the sea level model is based on the "sea level equation" [43] and includes subsequent improvements to allow for coastline migration and changes in Earth rotation [44,45]. GIA models allow the calculation of vertical and horizontal land motion, sea level, gravitational, rotation and stress changes associated with a selected ice-Earth model combination. Here we essentially use modelling results from Kierulf et al. [2] and show predictions of vertical land motion, which are compared to the GPS observations, and gravitational effects on sea level associated with GIA.

In their analysis, Kierulf et al. [2] test two different types of GIA models (finite element and normal mode) together with three different global ice models. We do not go into the details of the analysis of Kierulf et al. [2] but instead show results from the GIA model which they determine provides best fit to the GPS observations. Spherical harmonic expansions were truncated at degree and order 192.

The Earth model is one-dimensional and employs the normal mode method [46]. A Maxwell viscoelastic rheology is used and the Earth model is spherically symmetric, self-gravitating and compressible. The elastic and density structure are taken from seismic constraints [47] and depth parameterized with a resolution of $15-25 \mathrm{~km}$. The radial viscosity structure is depth parameterized more crudely into three layers: an elastic lithosphere (i.e., very high viscosity values are assigned), an isoviscous upper mantle bounded by the base of the lithosphere and the $670 \mathrm{~km}$ deep seismic discontinuity, and an isoviscous lower mantle continuing below this depth to the core mantle boundary.

The ice model is made of two parts: The Fennoscandian and Barents Sea ice sheets are represented by the model of Lambeck et al. [6], which has been shown to provide good fit to paleo sea level data from the region. For other areas of the globe, they use the ICE-3G ice sheet reconstruction of Tushingham and Peltier [48]. This is the same model setup as used in former BIFROST studies [1,28,37].

Past GIA modelling studies have used both paleo sea level data (e.g., [6,29]) and/or GPS observations (e.g., $[1,28,49])$ to help constrain Earth model parameters. These investigations have shown that it is not yet possible to uniquely constrain Earth's viscosity structure for the Fennoscandian region. Such studies, however, are able to provide a range of Earth parameter values that satisfy the various GIA observables. Based on values from former GIA studies, Kierulf et al. [2] examine laterally homogeneous Earth models bracketing 60-160 km for lithospheric thickness, $(0.1-40) \times 10^{20} \mathrm{~Pa}$ s for upper mantle viscosity and $(0.1-10) \times 10^{22} \mathrm{~Pa}$ s for lower mantle viscosity.

\subsection{Computing Regional Sea-Level Projections}

Observations show that past sea-level changes have been spatially variable, so we expect that future changes will also be of this nature [50]. Regional sea level can be substantially different from global mean changes owing to spatial variations in: (1) ocean density, ocean mass redistribution, and dynamics; (2) ocean mass changes and associated gravitational effects on sea level; and (3) vertical land motion and associated gravitational effects on sea level. We show regional sea-level projections 
for Norway's coastal municipalities using findings largely from IPCC AR5 [11] and CMIP5 model output [24]. Sea-level projections are given for the emissions scenarios RCP2.6, RCP4.5 and RCP8.5.

The difference between our results and those shown in IPCC AR5 are that we adopt a new VLM field with corresponding gravity changes (Section 3.1) and include an estimate of sea-level changes caused by the crustal displacements and gravitational effects of ocean mass redistribution (so-called self-attraction and loading). Here we make use of projections from the earth system model NorESM, where the self-attraction and loading contribution along the Norwegian coast was found to range from 1-2 cm for RCP2.6-8.5 over the 21st century [51].

Unlike in IPCC AR5, the contribution from changes in atmospheric pressure is not considered separately here. This contribution, known as the inverse barometer effect, is instead combined with the projected ocean density, ocean mass redistribution and circulation fields from the coupled Atmosphere-Ocean General Circulation Models (AOGCMs). The inverse barometer effect is relatively small. It is projected to be positive in the Arctic regions, up to $1.5 \mathrm{~cm}$ for RCP4.5 and $2.5 \mathrm{~cm}$ for RCP8.5 [52], but likely less than this along most of the Norwegian coast.

For the sea surface height CMIP5 model data the uncertainties are computed from the multi model ensemble spread (this is the steric/dyn signal given below). The ice sheet, glacier and land water storage regional uncertainties are calculated by multiplying their global uncertainties by the respective normalized "sea level equation" patterns [43-45]. The methods used to compute uncertainties associated with GIA (obsvlm and gravgia) are given in Sections 2.1 and 3.1. Gravitational effects on sea level due to ocean mass redistribution (sal) are described above (see also Richter et al. [51]). To combine the uncertainties, contributions that correlate with global warming have correlated uncertainties, so they are added linearly. Other contributions are assumed to be uncorrelated and are thus added in quadrature. The regional uncertainty is found by (adapted from Church et al. [11]):

$$
\begin{aligned}
\sigma_{\text {total }}^{2}=\left(\sigma_{\text {steric }}+\sigma_{\text {antsmb }}+\right. & \left.\sigma_{\text {greensmb }}\right)^{2}+\sigma_{\text {glaciers }}^{2}+\sigma_{\text {obsvlm }}^{2}+\sigma_{\text {gravgia }}^{2}+\sigma_{\text {grdwater }}^{2} \\
& +\sigma_{\text {antdyn }}^{2}+\sigma_{\text {greendyn }}^{2}+\sigma_{\text {sal }}^{2}
\end{aligned}
$$

steric/dyn = Global thermal expansion uncertainty and uncertainty associated with changes in ocean density, mass redistribution and circulation changes from the AOGCMs (includes the inverse barometer effect uncertainty).

antsmb $=$ Antarctic ice sheet surface mass balance uncertainty.

greensmb $=$ Greenland ice sheet surface mass balance uncertainty.

glaciers = glacier uncertainty.

obsvlm = observed vertical land motion uncertainty (here includes reference frame errors).

gravgia $=$ modelled gravity changes owing to GIA uncertainty.

grdwater $=$ land water storage uncertainty.

antdyn = Antarctic ice sheet rapid dynamics uncertainty.

greendyn $=$ Greenland ice sheet rapid dynamics uncertainty.

$s a l=$ self-attraction and loading uncertainty (gravitational effects of ocean mass redistribution).

Note that for each contribution $\sigma$ is the standard error except for grdwater, antdyn and greendyn. These have uniform probability distributions in the global projections and, therefore, the half-range of their distributions was used as $\sigma$.

\subsection{Methodology for Calculating Return Heights for Extreme Sea Levels}

In the above we have focussed on mean sea level. For practical purposes, however, it is often shorter-term sea-level changes that are of interest. Tides occur on a daily basis but their heights vary on a range of timescales (the different tidal constituents) and also along the coast. When quantifying 
coastal impacts and risk, the even higher extreme sea levels associated with storm surges need to be considered.

A return height for extreme sea levels is a height the sea level exceeds on average only once during a given return period (e.g., the 200-year return height). Return heights are typically calculated using statistical analysis of tide gauge data. Here we use the average conditional exceedance rate method for estimating the return heights [25]. Comparisons of alternative methodologies have found that the ACER method is suitable for estimating extreme sea level return periods for Norway and, furthermore, that it provides certain advantages compared to the Gumbel method and other classical methods [53,54]. Below we give an overview of the method, but for a detailed description the reader is referred to Næss and Gaidai [55] and Skjong et al. [54].

The difference between the ACER method and many of the classical methods is that the ACER method focuses on the exceedance rates of the extreme sea level instead of only the yearly maximum values. This makes the method less sensitive to gaps of missing data and outliers than some other methods. The ACER method also takes into account the dependency of the data, that is, that several subsequent peaks exceeding some level might be from the same extreme event. Working with extreme sea levels, this means that two subsequent high waters exceeding the given level are likely to be caused by the same storm surge as the storm surge often persists over more than one tidal cycle. Thus, we calculate the rate of which peaks exceed a given level given the condition that the previous peaks did not exceed; hence, we get a conditional exceeding rate.

More precisely, one defines the ACER function $\epsilon_{k}(\eta)$ as the rate at which the sea level crosses the threshold $\eta$ given $k-1$ previous non-exceedances. The ACER method attempts to capture the sub-asymptotic behaviour of the data by assuming that sub-asymptotically this function is given by:

$$
\epsilon_{k}(\eta)=q_{k}(\eta) \exp \left(-a_{k}\left(\eta-b_{k}\right)^{c_{k}}\right), \eta \geq \eta_{1}
$$

for a given level $\eta_{1}$ called the tail marker. In practice, the function $q_{k}(\eta)$ is varying slowly compared to the exponential function when $\eta$ is large, and it is therefore replaced by a constant value $q_{k}$.

We assume that one year of sea level data is one realization of the process. The conditional exceedance rate is calculated for discrete levels of $\eta$ and the average is taken as the estimate. Since the conditional upcrossings are assumed to be independent for a high enough value of $k$, the ACER function is calculated for different values of $k$ and the value of $k$ for which the process starts to converge is chosen. For sea level data this happens for $k=3$. A curve with the form given by Equation (2) is then fitted to the estimated ACER functions, determining the parameters $q_{k}, b_{k}, a_{k}$ and $c_{k}$. The confidence intervals are found in a similar way, by fitting curves to the lower and upper confidence bounds of the estimate of the ACER function. The different return heights can now be estimated by extrapolating the fitted curve to high values of $\eta$. The return height $z_{m}$ where $m$ is the return period is given by the following formula, where $N$ is the average number of peaks in the data during one year:

$$
z_{m}=b_{k}+\left[\frac{1}{a_{k}}\left(\ln \left(q_{k} N\right)-\ln \left[-\ln \left(1-\frac{1}{m}\right)\right]\right)\right]^{\frac{1}{c_{k}}}
$$

Return heights are available for all 23 Norwegian tide gauges except Mausund, which has not been fully integrated in the tide gauge network and has a shorter time series than the other gauges. Return heights given in this paper are calculated using data up to December 2014 and are currently the official levels for use in coastal planning [25]. Note that return heights are normally updated every 5 years; this ensures that changes in: (1) the frequency and height of extreme sea levels; and (2) the mean sea level are taken into account. The 20-, 200- and 1000-year return heights are given in Table 1 together with the first year of data used for each tide gauge. Figure 3 shows all return periods with confidence intervals for the six key locations. 
Table 1. Return heights for extreme sea levels calculated for the Norwegian tide gauges, given in meters above mean sea level (1996-2014). The 5\% and 95\% confidence levels are given in parentheses.

\begin{tabular}{ccccc}
\hline Tide Gauge & Start & 20-Year & 200-Year & 1000-Year \\
\hline Vardø & 1947 & $2.19(2.12,2.26)$ & $2.37(2.28,2.46)$ & $2.48(2.37,2.58)$ \\
Honningsvåg & 1970 & $2.01(1.90,2.08)$ & $2.21(2.05,2.30)$ & $2.33(2.14,2.44)$ \\
Hammerfest & 1957 & $2.01(1.91,2.07)$ & $2.19(2.03,2.27)$ & $2.29(2.11,2.39)$ \\
Tromsø & 1952 & $2.03(1.97,2.07)$ & $2.21(2.13,2.26)$ & $2.32(2.22,2.37)$ \\
Harstad & 1952 & $1.75(1.68,1.79)$ & $1.92(1.82,1.98)$ & $2.03(1.91,2.09)$ \\
Andenes & 1991 & $1.84(1.70,1.93)$ & $2.08(1.88,2.20)$ & $2.23(1.99,2.38)$ \\
Kabelvåg & 1988 & $2.45(2.30,2.54)$ & $2.71(2.49,2.82)$ & $2.87(2.60,3.00)$ \\
Narvik & 1931 & $2.59(2.46,2.65)$ & $2.85(2.65,2.94)$ & $3.02(2.77,3.11)$ \\
Bodø & 1949 & $2.25(2.16,2.31)$ & $2.47(2.35,2.55)$ & $2.61(2.47,2.69)$ \\
Rørvik & 1969 & $2.08(1.95,2.14)$ & $2.30(2.12,2.38)$ & $2.43(2.22,2.53)$ \\
Trondheim & 1989 & $2.21(2.10,2.27)$ & $2.38(2.24,2.45)$ & $2.49(2.33,2.57)$ \\
Heimsjø & 1928 & $1.94(1.87,1.99)$ & $2.10(2.00,2.17)$ & $2.20(2.08,2.28)$ \\
Kristiansund & 1952 & $1.80(1.72,1.84)$ & $1.96(1.85,2.02)$ & $2.06(1.93,2.13)$ \\
Ålesund & 1961 & $1.70(1.60,1.76)$ & $1.88(1.73,1.95)$ & $1.98(1.80,2.07)$ \\
Måløy & 1943 & $1.53(1.48,1.57)$ & $1.66(1.60,1.71)$ & $1.74(1.66,1.80)$ \\
Bergen & 1915 & $1.29(1.25,1.32)$ & $1.41(1.35,1.46)$ & $1.48(1.41,1.54)$ \\
Stavanger & 1919 & $1.01(0.95,1.04)$ & $1.15(1.06,1.19)$ & $1.23(1.13,1.29)$ \\
Tregde & 1927 & $0.95(0.89,1.00)$ & $1.12(1.01,1.19)$ & $1.23(1.09,1.32)$ \\
Helgeroa & 1965 & $1.26(1.12,1.34)$ & $1.51(1.29,1.62)$ & $1.67(1.39,1.81)$ \\
Oslo & 1914 & $1.53(1.39,1.62)$ & $1.86(1.62,1.99)$ & $2.09(1.77,2.25)$ \\
Oscarsborg & 1953 & $1.42(1.29,1.50)$ & $1.67(1.49,1.76)$ & $1.83(1.61,1.93)$ \\
Viker & 1990 & $1.39(1.18,1.52)$ & $1.66(1.35,1.84)$ & $1.83(1.46,2.05)$ \\
\hline
\end{tabular}
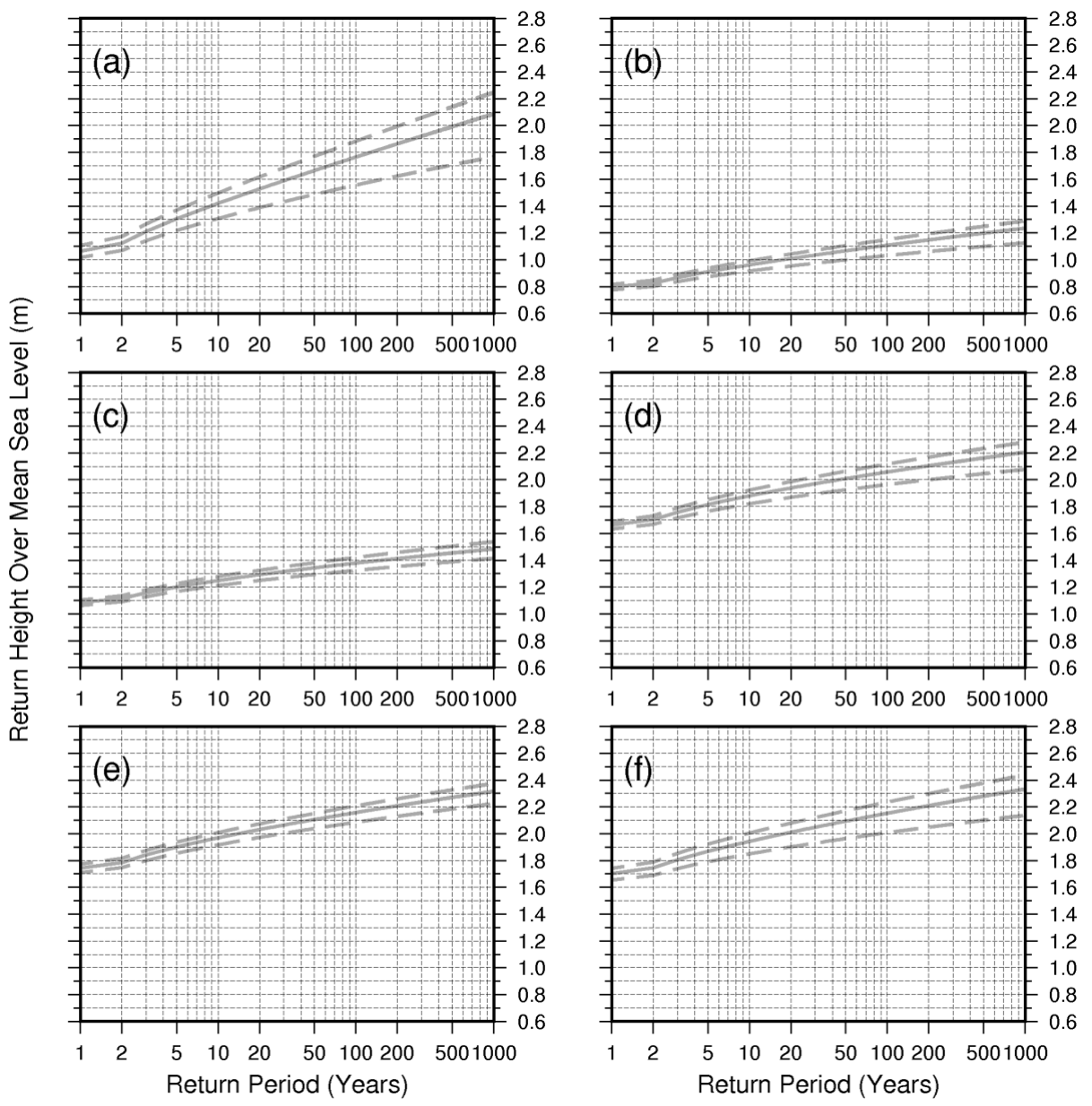

Figure 3. Return heights for extreme sea levels for the six key locations: (a) Oslo; (b) Stavanger; (c) Bergen; (d) Heimsjø; (e) Tromsø; and (f) Honningsvåg. Dashed lines are the 5\% and 95\% confidence intervals. 
Since the amplitude and time of the tide vary along the Norwegian coast, the return heights calculated for a particular tide gauge cannot simply be applied to another point of the coastline. Hence, we need to be able to extrapolate these extreme sea levels along the coast. To assist this extrapolation procedure, there are several hundred shorter data series available from temporary tide gauges, dating from the beginning of the 20th century to present-day. These data series are analysed so that the relationship between the tidal behaviour in the area of a temporary tide gauge and that of a permanent tide gauge can be quantified. Following this procedure, the Norwegian coastline has been divided into zones of similar tidal properties. When extrapolating the water level to a point away from the permanent tide gauges, therefore, the astronomical tide is first determined using the tidal zones as described above and then added to the meteorological effect as seen at the closest permanent tide gauge(s). This approach assumes that the meteorological conditions affecting sea level are large-scale phenomena that have a similar effect on sea level over a large area and vary smoothly. The return heights are then estimated using the corrected water level series, in the same way as for the permanent tide gauges. Figure 4 shows water levels extrapolated to the 290 coastal municipalities in Norway.
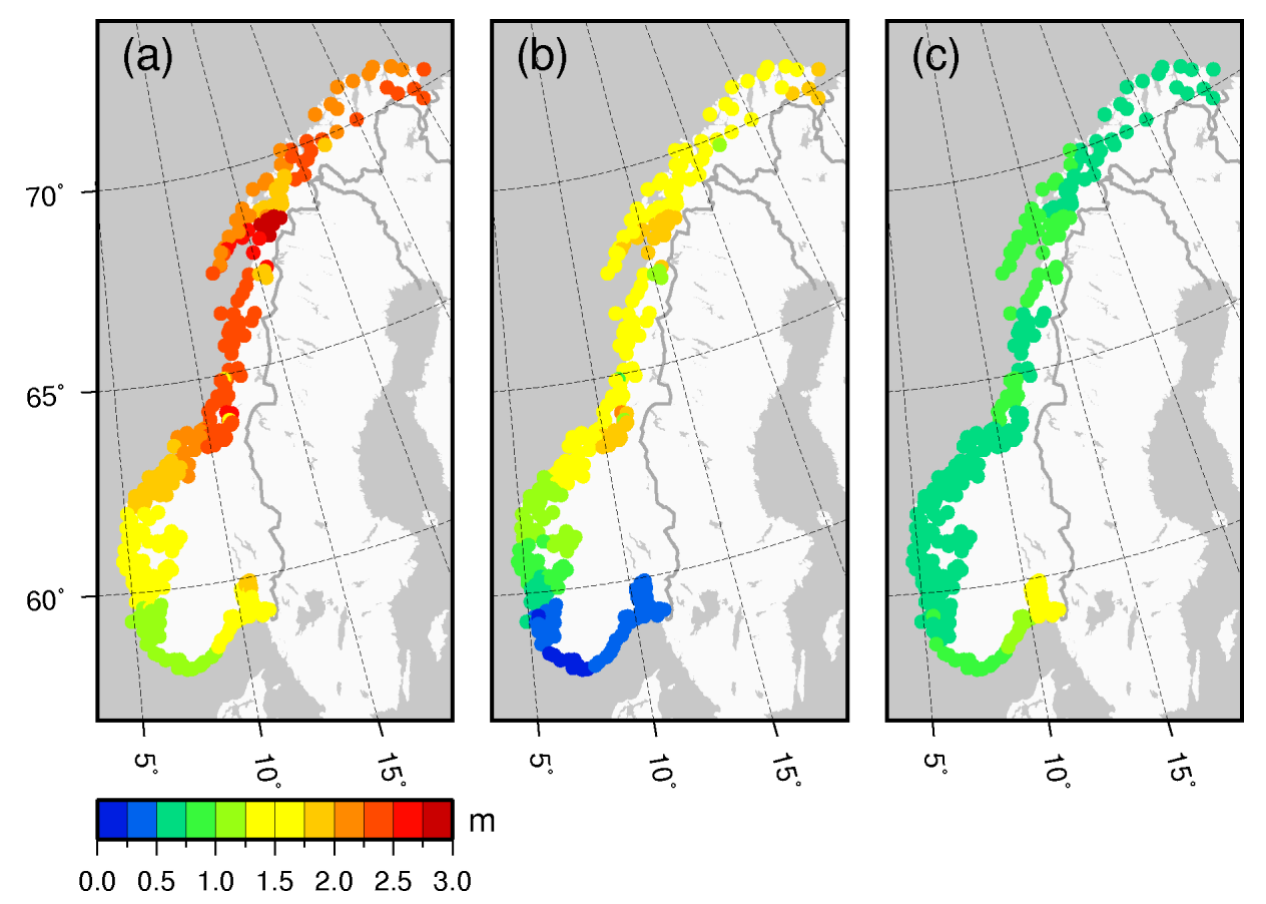

Figure 4. Water levels extrapolated to the 290 coastal municipalities in Norway: (a) the 200-year return height in meters above mean sea level; (b) highest astronomical tide (HAT) in meters above mean sea level; and (c) the 200-year return height in meters above HAT in order to compare the significance of the extreme levels.

\subsection{Combining Storm Surge Statistics with Sea-Level Projections}

Sea-level projections can be combined with the storm surge statistics to provide "allowances" (see, e.g., Hunter [16] and Hunter et al. [17]). Here, we adapt this approach for use with the ACER method for calculating the return heights. We define the expected number of exceedances of a level $z$ over a given time period to be given by:

$$
N_{A C}=N q \exp \left(-a(z-b)^{c}\right)
$$

where $N, q, a, b$ and $c$ are the ACER parameters for a given $k$ as described above. We now assume that mean sea level is raised by $\Delta z+z^{\prime}$, where $\Delta z$ is the mean value of the sea-level rise and $z^{\prime}$ is a random variable with a probability distribution given by $P\left(z^{\prime}\right)$ and a zero mean. As our level $z$ has now been 
reduced by $\Delta z+z^{\prime}$, we try to find how much we have to raise this level with in order to keep the same exceedance rate as $z$ had before this rise of the mean sea level. This amount will be the allowance $A$. We denote the overall number of excedances of the level $z-\Delta z-z^{\prime}+A$ as $N_{o v, A C}$, that is,

$$
N_{o v, A C}=\int_{-\infty}^{\infty} P\left(z^{\prime}\right) N q \exp \left(-a\left(z-\Delta z-z^{\prime}+A-b\right)^{c}\right) d z^{\prime}
$$

The objective is to calculate the allowance $A$ so that $N_{o v, A C}=N_{A C}$, that is, the expected number of exceedances before and after the sea level rise remains constant. By manipulating Equation (5) we obtain

$$
N_{o v, A C}=N q \exp \left(-a(z-b)^{c}\right) \int_{-\infty}^{\infty} P\left(z^{\prime}\right) \exp \left(a(z-b)^{c}\right) \exp \left(-a\left(z-\Delta z-z^{\prime}+A-b\right)^{c}\right) d z^{\prime}
$$

Thus, we have $N_{o v, A C}=N_{A C}$ if

$$
\int_{-\infty}^{\infty} P\left(z^{\prime}\right) \exp \left(a(z-b)^{c}\right) \exp \left(-a\left(z-\Delta z-z^{\prime}+A-b\right)^{c}\right) d z^{\prime}=1
$$

It is not possible to eliminate the return height $z$ from Equation (7). Thus, by combing the approach of Hunter [16] with the ACER method, instead of the Gumbel method, it is no longer the case that the allowance remains the same for any return height $z$ given.

In a preliminary test of the method and its application to Norway, we examine the case of a future sea level rise assuming a normal uncertainty distribution with zero mean and a standard error $\sigma$ such that

$$
P\left(z^{\prime}\right)=\frac{1}{\sigma \sqrt{2 \pi}} \exp \left(-\frac{z^{\prime 2}}{2 \sigma^{2}}\right)
$$

\section{Results}

\subsection{Present-Day Vertical Land Motion in Norway}

\subsubsection{Results from GIA Modelling}

The goodness-of-fit between the GPS observations and modelled vertical crustal velocities is tested for changes in Earth model parameters. In total 1089 Earth models are tested (model output from Kierulf et al. [2]) and the best fitting Earth model is determined to have $140 \mathrm{~km}$ lithospheric thickness, $7 \times 10^{20}$ Pa s upper mantle viscosity and $4 \times 10^{21} \mathrm{~Pa}$ s lower mantle viscosity. Predicted vertical velocities generated using the best-fit GIA model (Figure 5) show a familiar pattern of land motion (e.g., [1]). All of mainland Norway is predicted to be uplifting; rates along the Norwegian coast vary between 1 and $5 \mathrm{~mm} /$ year. Visual inspection of Figure 5 shows that the pattern of modelled uplift is, broadly speaking, in good agreement with the observations. At 44 of the 92 Norwegian GPS stations, the model fits to within one-sigma of the observations.

Selecting a subset of 10 stations where we have long time series and are confident in the velocity estimates, we find the RMS error between the model and GPS measurements is $0.9 \mathrm{~mm} /$ year (this test is useful for a comparison later on). Residuals between the best-fit GIA model and GPS data show that the model tends to overpredict rates of uplift in the middle of Norway, around $64^{\circ} \mathrm{N}$ (Figure $5 \mathrm{~b}$ ).

In order to incorporate the GIA results within our regional sea-level projections it is necessary to define a mean GIA field along with lower and upper $90 \%$ uncertainty bounds. For modelled GIA we opt to define the mean and uncertainty bounds as follows. Of the 1089 Earth models tested in the analysis of Kierulf et al. [2] a subset of 61 are identified as having comparably good fit to the observations and classified as the best-fit models (at the one standard deviation confidence level). Using this subset of 61 models, we calculate the mean and 90\% uncertainty bounds from the spread in the vertical crustal velocity field predictions. In this manner, we obtain a model uncertainty which is 
tightly constrained to the GPS observations. This approach is preferable to simply using the full range of 1089 Earth models tested as the vertical velocity predictions are highly sensitive to the assumed Earth structure. The average GIA model uncertainty for the coastal municipalities is $\pm 0.2 \mathrm{~mm}$ /year (standard error). It is important to note that the GIA uncertainty given here only accounts for changes in Earth model parameters (i.e., it ignores possible errors in the assumed ice loading history).

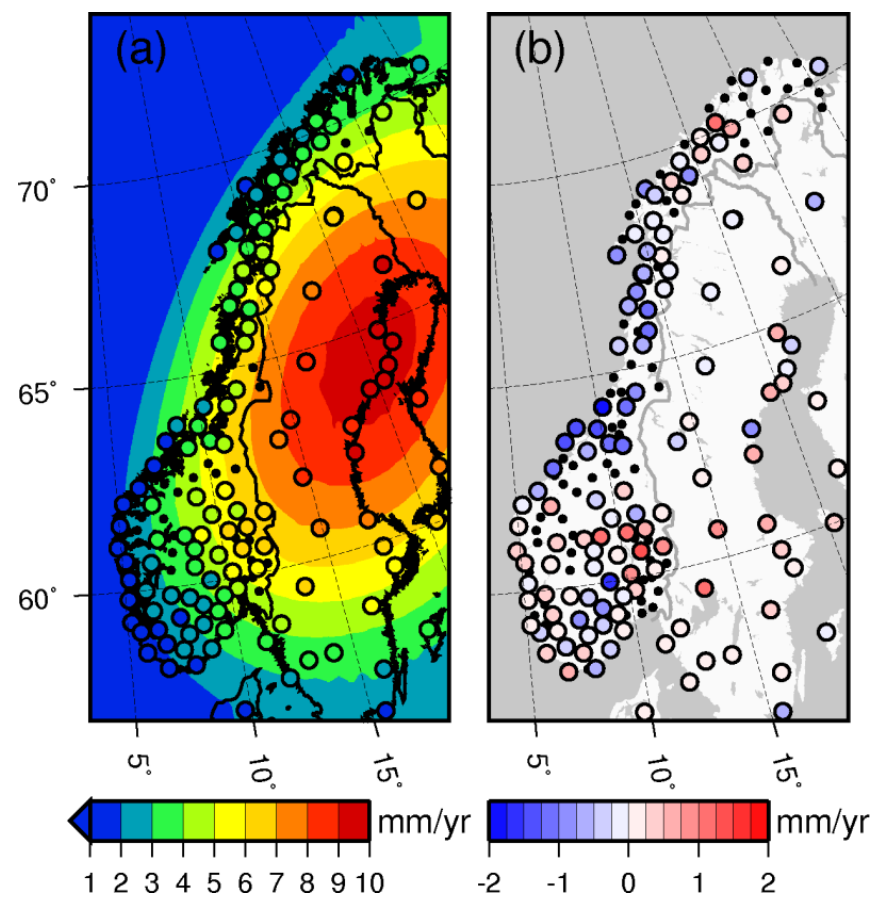

Figure 5. (a) Modelled vertical land motion from the best-fit GIA model. The vertical velocities from the GPS observations are shown as circles. Black dots mark stations with less than three years of data, these observations are not included in this study as they are considered unreliable. (b) Residuals (observed minus modelled).

As mentioned, we also take into account gravitational effects on sea level associated with GIA. Ocean surface height changes are typically between $5 \%$ and $10 \%$ of the vertical land motion signal [56] so this is a relatively small effect. We calculate the mean field and $90 \%$ uncertainty bounds for ocean surface height changes associated with GIA. This is done with same subset of 61 Earth models used to calculate the mean and $90 \%$ uncertainty for the vertical land motion rates as above. For the mean field, modelled ocean surface changes associated with GIA vary between 0.2 and $0.5 \mathrm{~mm} /$ year along the Norwegian coast, the average model uncertainty is $\pm 0.03 \mathrm{~mm} /$ year (standard error).

\subsubsection{Results from Least-Squares Collocation}

In our second approach, we base our calculation purely on geodetic observations and use a method of least-squares collocation to combine the levelling and GPS observations and determine VLM in Norway (e.g., [33]). Our mean VLM solution is shown in Figure 6a and residuals with the GPS data shown in Figure 6b. The pattern of uplift based purely on the combined observations is broadly similar to our GIA model. Note that, for the least-squares collocation method, the input data from levelling and GPS act to mutually control each other, which increases the reliability of the VLM solution. In addition, the method filters the observations making the solution more robust to errors and outliers (see [33]). 


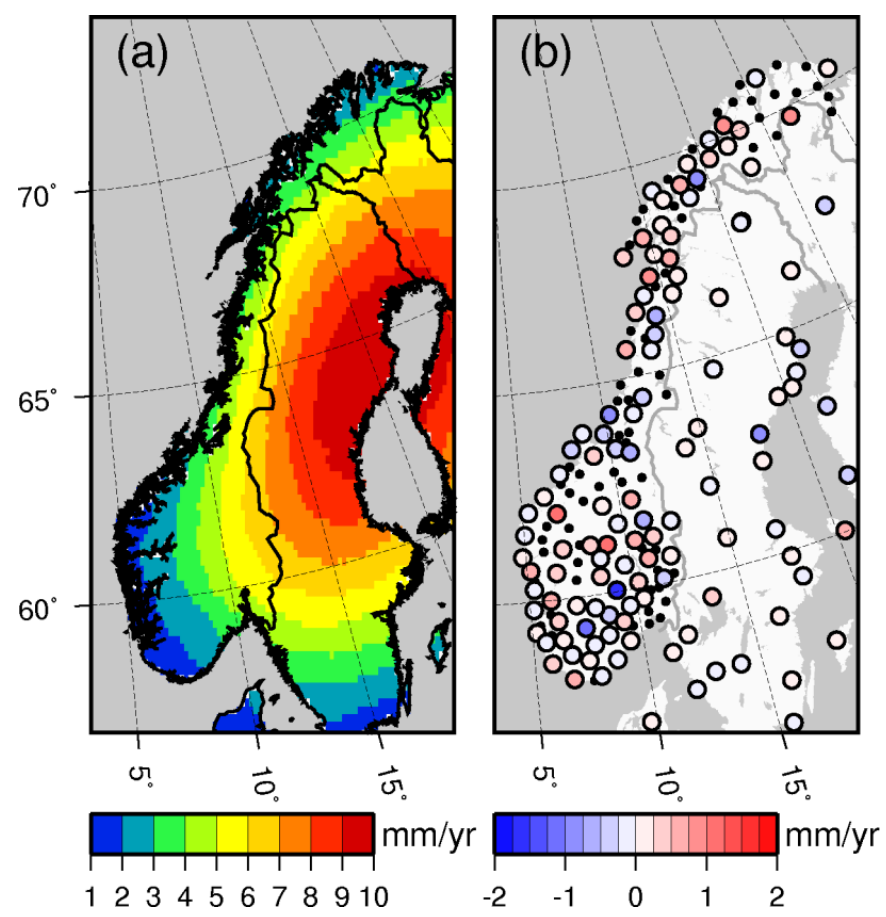

Figure 6. Vertical land motion determined from least-squares collocation of the levelling and GPS observations for: (a) our mean solution; and (b) the residuals (GPS observations-mean solution). Black dots mark stations with less than three years of data, these observations are not included in this study as they are considered unreliable.

In a test of the least-squares collocation method, we recalculate the VLM solution but omit a subset of 10 GPS stations where we have long time series and are confident in the velocity estimates (the same test as performed for the GIA model and using the same 10 GPS stations). For these 10 Norwegian stations, the RMS error between the recalculated VLM solution at the GPS observations is $0.3 \mathrm{~mm} /$ year. This is an encouraging result and gives us confidence in the solution where observations are few or lacking. From our least-squares collocation solution we calculate the mean field and $90 \%$ uncertainty bounds for the Norwegian coastal municipalities, the average uncertainty for these locations is $\pm 0.2 \mathrm{~mm} /$ year (standard error).

\subsubsection{Comparison of GIA Model and Least-Squares Collocation Approach}

We have shown two different approaches to predicting VLM for the coastal municipalities: (1) a GIA model that is calibrated to the GPS observations; and (2) compute land motion by combining the levelling and GPS observations through least-squares collocation. It is of clear interest to determine which method best describes land motion for coastal Norway and, therefore, which is preferable when calculating future sea-level changes. In a simple test, we calculated the RMS error between the two different solutions and 10 Norwegian GPS stations where we have long time series and are confident in the velocity estimates (see also above). The RMS errors for the GIA model and least-squares collocation solutions are $0.9 \mathrm{~mm} /$ year and $0.3 \mathrm{~mm} /$ year, respectively. This comparison therefore indicates that the least-squares collocation approach performs best, i.e., the method has a better accuracy in predicting VLM in areas where we do not have observations.

For the 290 coastal municipalities we find that the average uncertainties on the GIA model and least-squares collocation solutions are the same (both $\pm 0.2 \mathrm{~mm} /$ year). As a consequence of the method and additional constraint of the levelling data, the average uncertainty on the least-squares collocation solution is somewhat less than that we could expect to obtain from the GPS stations alone (the average uncertainty on the 92 GPS velocity estimates in Norway is $\pm 0.75 \mathrm{~mm} /$ year). For the GIA model, the 
uncertainty is tightly constrained by the GPS observations and, as discussed, only accounts for changes in Earth model parameters. Better quantifying the GIA uncertainty is a challenging task but more rigorous methods are forthcoming (e.g., [57]). Finally, it is important to recognise that neither of these uncertainty estimates account for possible systematic errors in the reference frame. We address this point below.

We opt to use the least-squares collocation solution to define our vertical velocity field for use in the sea-level projections. There are a few caveats with the approach that should be highlighted. Firstly, by using the observed vertical land motion in our sea-level projections, we assume that the observed rates will persist unchanged over the 21st century. We argue that this is a reasonable assumption as GIA dominates present-day vertical land motion in Norway (e.g., $[1,2,28,39,49])$ and that the viscoelastic response time of the Earth is so long we would not expect any significant changes in the uplift rates over next 100 years. Furthermore, the generally good fit between GIA model and GPS observations shows we have a good understanding of physical process causing uplift and gives us confidence that the observations can be extrapolated in this way.

As shown in Figure 5, however, there are some significant misfits between the GIA model and observations. (We also expect similar differences between the GIA model and least-squares collocation solution but this is not specifically examined here). Such residuals may be explained by: (1) errors in the GIA model, for example, that the ice loading is incorrect or that lateral variations in the Earth model should considered; (2) other geophysical processes contributing to vertical land motion, for example, recent work by Olesen et al. [30] identified neotectonic deformations of around $1 \mathrm{~mm} /$ year in the north of Norway; and (3) errors in the GPS and/or levelling observations. As noted above, four GPS stations have been removed from our final results as the data suggests they may be unstable. One advantage of using the least-squares collocation approach means that, to some extent, our solution is less sensitive to outliers. These issues should be kept in mind when interpreting the results.

\subsubsection{Our GIA Solution and Comparison to IPCC AR5}

Our full GIA solution, as a contribution to RSL change, is the VLM field determined from least-squares collocation added to the modelled gravitational effects on sea level associated with GIA. When computing uncertainties on our GIA solution, note that we include systematic errors on the reference frame's $z$-drift $(0.5 \mathrm{~mm} /$ year $)$ and scale error $(0.3 \mathrm{~mm} /$ year $)$. Taken together, the average uncertainty on our GIA solution is $0.6 \mathrm{~mm} /$ year.

The mean GIA field in IPCC AR5 is evaluated as the mean of the ICE-5G model [34] and the ANU-ICE model (Lambeck et al. [6] and subsequent improvements). These GIA models are based upon global ice sheet reconstructions where the loading history of the ice sheets is essentially inferred from paleo sea level observations. The one standard error of the GIA field is taken as the difference between the separate models. This approach is adequate when considering regional patterns of sea-level change on a global scale, as in IPCC AR5, but here we are focussed on changes for Norway and at a local level. It is also of interest to compare our GIA solution (based on geodetic observations) to the modelled solution applied in IPCC AR5.

In Figure 7, we show the future RSL contribution from our GIA solution and that used in IPCC AR5 at our six key locations. At most locations the solutions agree to within their respective uncertainties. Our GIA solution has an almost uniform uncertainty, but the IPCC AR5 uncertainty is small in some locations (e.g., Oslo) but much larger in others (e.g., Tromsø). This simply reflects differences between the ICE-5G and ANU models. We find that the mean IPCC AR5 GIA solution lies within our $90 \%$ uncertainty bounds for 270 of the 290 coastal municipalities (figure not shown). Our mean GIA solution gives on average $4 \mathrm{~cm}$ higher values than that applied in IPCC AR5; i.e., our mean GIA solution indicates on average a smaller RSL fall. We have more confidence in our GIA solution, the values and uncertainties being essentially based upon the GPS and levelling observations. 


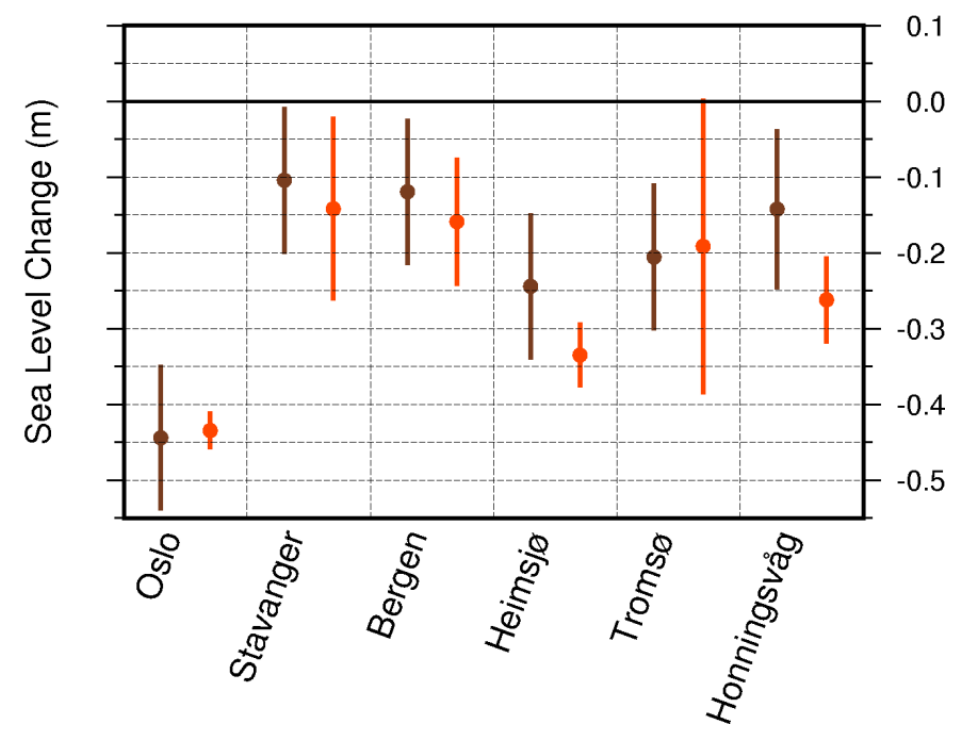

Figure 7. Regional relative sea-level change (m) due to GIA and associated gravitational effects over the period 1986-2005 to 2081-2100 for our GIA solution (brown) and IPCC AR5 (red). Dots show mean values and vertical bars the $5 \%$ to $95 \%$ uncertainty.

\subsection{Regional Sea-Level Projections}

Here we present regional sea-level projections for Norway using model output from the CMIP5 and for the emission scenarios RCP2.6, RCP4.5 and RCP8.5. The projections are given with corresponding $5 \%$ to $95 \%$ ensemble spread, these ranges are defined as the likely ranges in IPCC AR5 $(p>66 \%)$.

\subsubsection{Contributions to 21st Century Sea-Level Changes for Norway}

The separate contributions to projected sea level are shown in Figure 8 for RCP4.5. This shows that the largest projected contributions and also largest uncertainties are from rapid ice dynamics in Antarctica, the steric/dyn signal and observed vertical land motion. The observed vertical land motion signal shows the largest variation between the six tide gauge sites examined, indicating that this signal will dominate the pattern of 21st century sea-level changes along the Norwegian coast. The steric/dyn and glacier projections contribute to the spatial variability to a lesser extent.

Changes in the distribution of mass on the Earth's surface produces a non-uniform sea level pattern due to gravitational changes [43]. This sea level response is often referred to as a "fingerprint" as it can be used to identify the source and size of ice mass variations. As Norway sits in the near field of Greenland, the projections indicate a small or even negative sea-level change along the coast. That is, owing to gravitational changes, Norway is predicted to experience a sea-level change between $-40 \%$ and $10 \%$ of the global average sea-level rise due to Greenland surface mass balance loss. On the other hand, ice mass losses in Antarctica are predicted to produce an above average sea-level change for Norway.

Modelling results indicate an above average steric/dyn sea-level rise for Norway over the 21st century but with relatively large uncertainties attached to the projections (Figure 8). We note the results from the CMIP5 ensemble indicate that areas that are projected to have above average sea-level change coincide with areas that have larger uncertainties [58]. That appears to be the case for Norway. Past modelling studies have focused on identifying the contributing factors to regional differences in projected ocean density and circulation changes (e.g., [53,59-61]). These generally show that in the nearby North Atlantic positive thermosteric changes are partially compensated by a negative halosteric signal, whereas, in the Arctic Ocean, the halosteric term is positive and dominates due to 
ocean freshening. Related to these steric changes is a mass redistribution term that could be important for the shallow shelf seas around Norway [51].
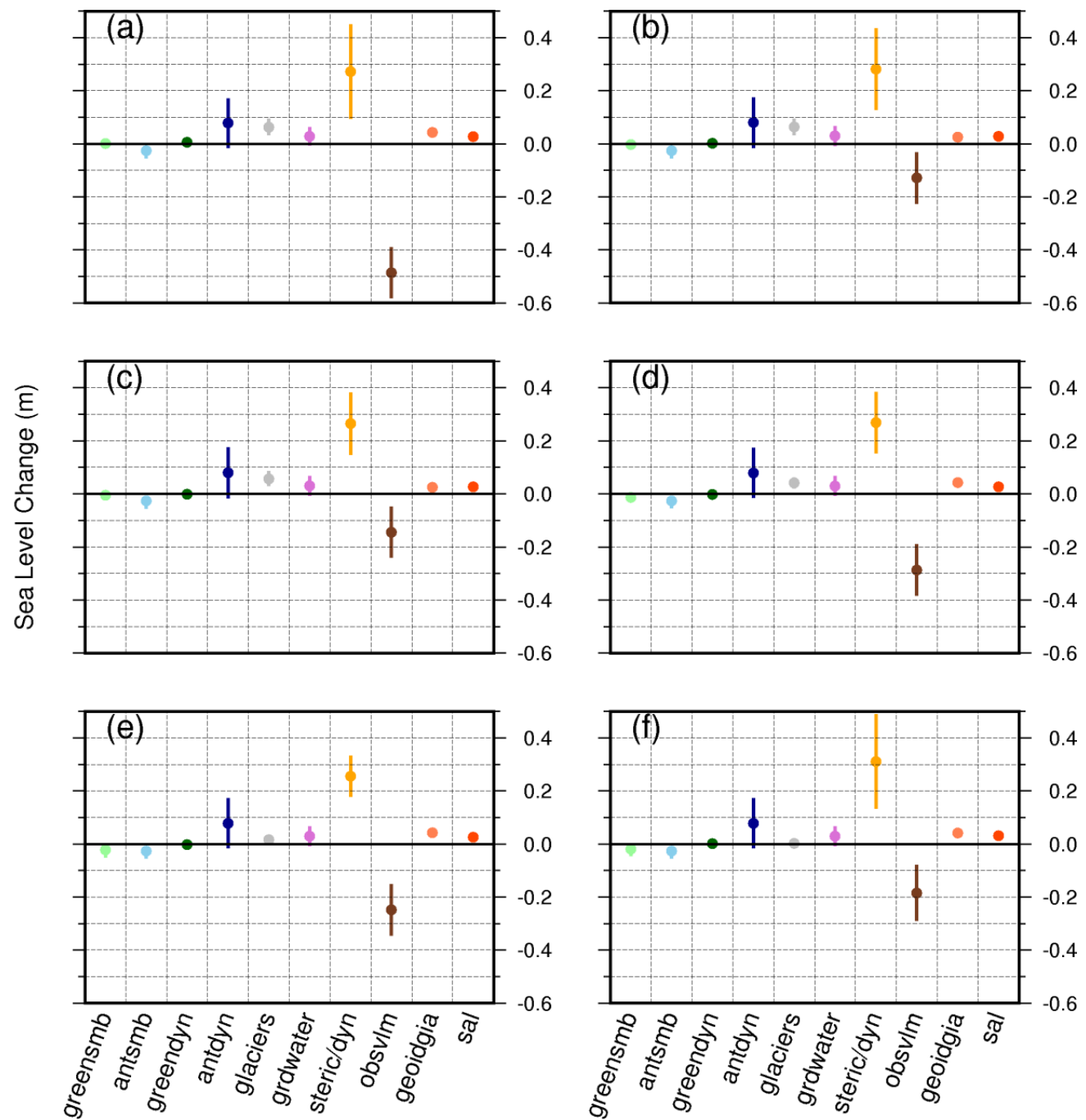

Figure 8. Contributions to projected relative sea-level change for RCP4.5 over the period 1986-2005 to 2081-2100 for the six key locations: (a) Oslo; (b) Stavanger; (c) Bergen; (d) Heimsjø; (e) Tromsø; and (f) Honningsvåg. The ensemble mean and spread ( $5 \%$ to $95 \%$ ) are shown by the circles and vertical bars, respectively.

\subsubsection{Projected 21st Century Sea-Level Changes for Norway}

Here we present our regional relative sea-level projections (Figure 9 and Table 2) which take account of changes to the contributions described in Sections 2.2 and 3.2.1 The projections show, unsurprisingly, that the pattern of twenty-first century relative sea-level changes for Norway is governed by GIA. For all RCPs, projected ensemble mean changes indicate that the majority of Norway will experience a RSL rise over the period 1986-2005 to 2081-2100. Thus, climate driven sea-level rise will dominate over VLM over the next 100 years. 

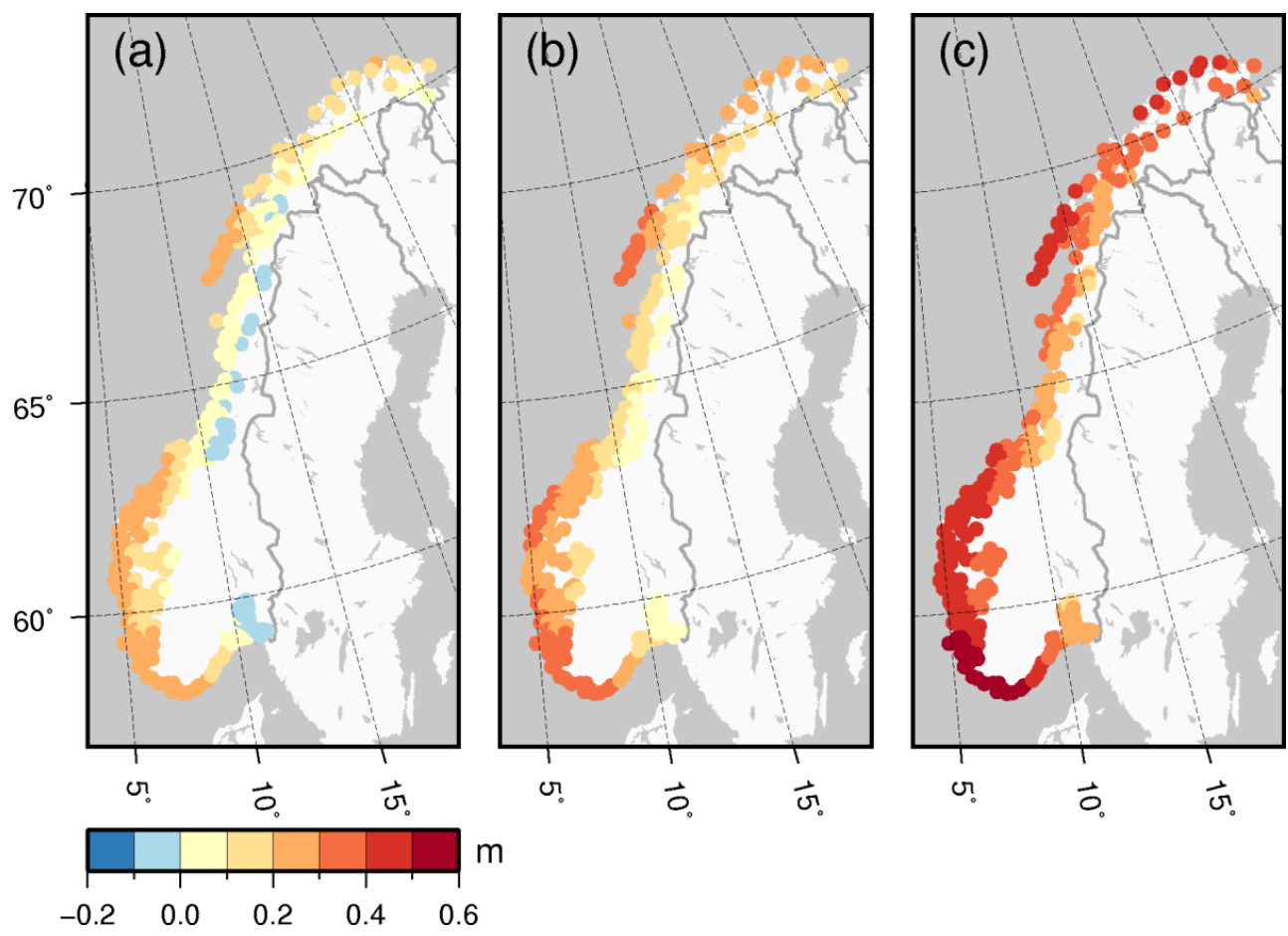

Figure 9. Projected ensemble mean relative sea-level change (m) for the 290 coastal municipalities in Norway over the period 1986-2005 to 2081-2100 for: (a) RCP2.6; (b) RCP4.5; and (c) RCP8.5.

Table 2. Comparison of mean relative sea-level projections at six key locations for the period 1986-2005 to $2081-2100$ and the period $1986-2005$ to 2100 . The $5 \%$ to $95 \%$ ensemble spread is given in the parentheses. Units are in centimetres.

\begin{tabular}{ccccccc}
\hline Location & $\begin{array}{c}\text { RCP2.6 } \\
\mathbf{2 0 8 1 - 2 1 0 0}\end{array}$ & RCP2.6 2100 & $\begin{array}{c}\text { RCP4.5 } \\
\mathbf{2 0 8 1 - 2 1 0 0}\end{array}$ & RCP4.5 2100 & $\begin{array}{c}\text { RCP8.5 } \\
\mathbf{2 0 8 1 - 2 1 0 0}\end{array}$ & RCP8.5 2100 \\
\hline Oslo & $-7(-32$ to 16$)$ & $-8(-36$ to 19$)$ & $0(-25$ to 24$)$ & $0(-29$ to 28$)$ & $18(-12$ to 47$)$ & $23(-11$ to 56$)$ \\
Stavanger & $28(5$ to 50$)$ & $30(4$ to 54$)$ & $35(12$ to 58$)$ & $38(12$ to 63$)$ & $52(25$ to 79$)$ & $59(28$ to 90$)$ \\
Bergen & $23(3$ to 42$)$ & $23(2$ to 45$)$ & $31(10$ to 51$)$ & $33(11$ to 55$)$ & $48(23$ to 72$)$ & $53(26$ to 80$)$ \\
Heimsjø & $7(-17$ to 27$)$ & $7(-14$ to 28$)$ & $16(-5$ to 37$)$ & $17(-6$ to 40$)$ & $30(8$ to 57$)$ & $36(8$ to 65$)$ \\
Tromsø & $6(-10$ to 23$)$ & $8(-11$ to 27$)$ & $15(-3$ to 34$)$ & $15(-5$ to 35$)$ & $29(5$ to 55$)$ & $32(3$ to 63$)$ \\
Honningsvåg & $18(-7$ to 44$)$ & $20(-8$ to 48$)$ & $27(0$ to 53$)$ & $29(-2$ to 59$)$ & $43(10$ to 76$)$ & $48(11$ to 86$)$ \\
\hline
\end{tabular}

Projected ensemble mean RSL changes along the Norwegian coast over the period 1986-2005 to 2081-2100 are, depending on location, for RCP2.6 between -0.10 and $0.30 \mathrm{~m}$; for RCP4.5 between 0.00 and $0.35 \mathrm{~m}$; and for RCP 8.5 between 0.10 and $0.55 \mathrm{~m}$. Expressed as a percentage of global mean change, mean regional RSL changes for Norway are for RCP2.6 from $-30 \%$ to $70 \%$ (global mean change of $0.40 \mathrm{~m}$ ); for RCP4.5 from $-10 \%$ to $75 \%$ (global mean change of $0.47 \mathrm{~m}$ ); and for RCP 8.5 from $20 \%$ to $85 \%$ (global mean change of $0.63 \mathrm{~m}$ ). For all RCPs the mean regional RSL change is therefore projected to be below the global mean.

Over the period 1986-2005 to 2081-2100 the ensemble mean RSL change averaged over the coastal municipalities is for RCP2.6 $0.1 \mathrm{~m}$ (90\% uncertainty bounds are -0.10 to $0.35 \mathrm{~m})$, for RCP4.5 $0.2 \mathrm{~m}$ ( -0.05 to $0.45 \mathrm{~m})$ and for RCP8.5 $0.35 \mathrm{~m}(0.10$ to $0.65 \mathrm{~m})$. If we ignore the effects of GIA, i.e., we look at the projected sea surface height change, these numbers are for RCP2.6 $0.35 \mathrm{~m}(0.15$ to $0.55 \mathrm{~m})$, for RCP4.5 $0.4 \mathrm{~m}(0.20$ to $0.65 \mathrm{~m})$ and for RCP8.5 $0.6 \mathrm{~m}(0.30$ to 0.85$)$. For the different RCPs the projected sea surface height changes are between $80 \%$ and $90 \%$ of the global mean change. This is because the projected above average input from steric/dyn sea-level changes and the rapid ice dynamic 
contribution from Antarctica are more than compensated for by the below average contributions from Greenland and glaciers.

Examining the projected RSL time series (Figure 10) shows that there are only small differences between the RCPs up until 2050. Going towards 2100 the separate projections from the RCPs begin to diverge but there are still large overlaps between their respective uncertainties. In fact, inspection of the vertical bars in Figure 10 shows that differences between the ensemble means for the different RCPs are somewhat smaller than the projections ensemble spread ( $5 \%$ to $95 \%$ ).

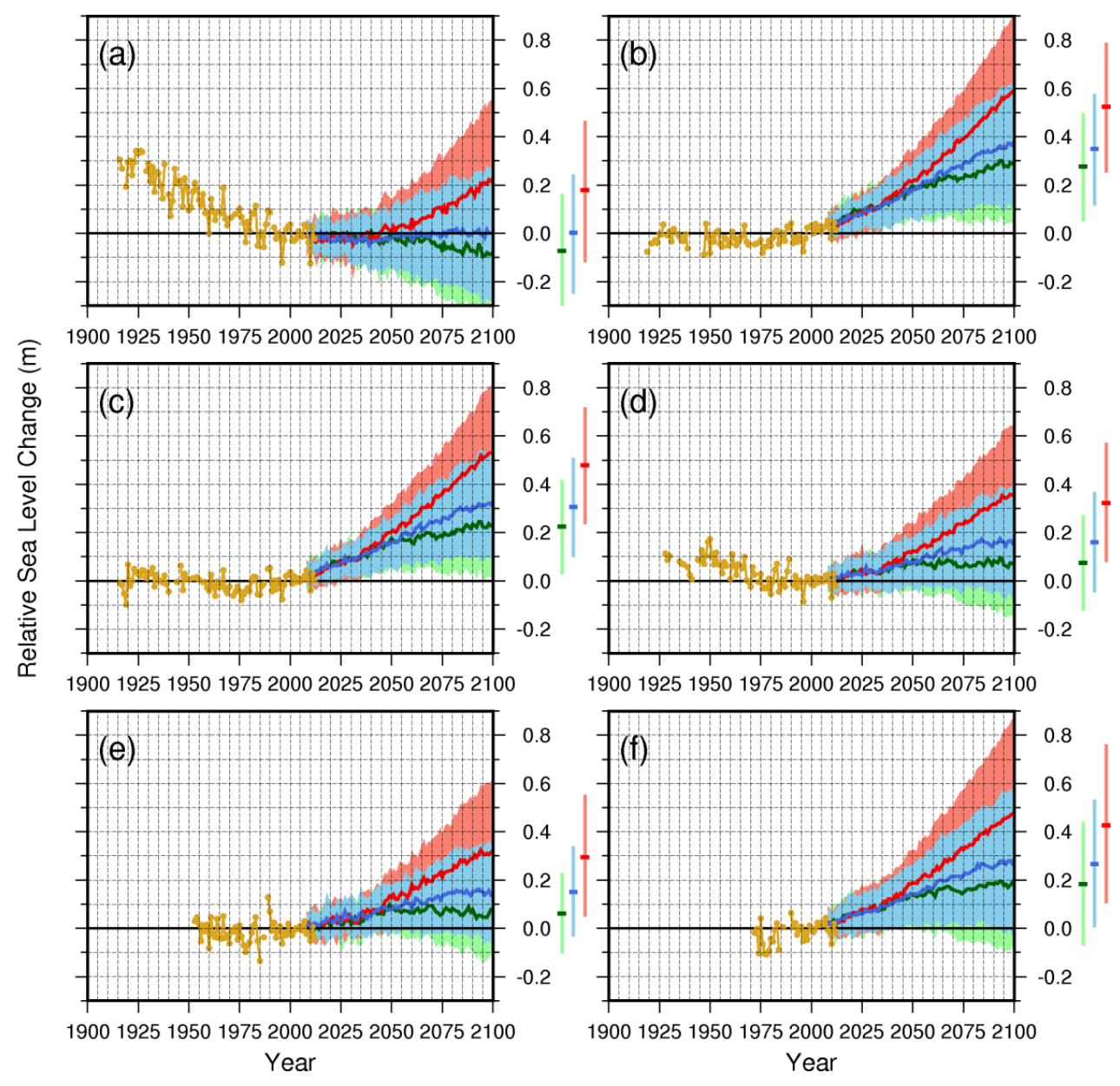

Figure 10. Relative sea-level projections for RCP2.6 (green), RCP4.5 (blue) and RCP8.5 (red) for the six key locations: (a) Oslo; (b) Stavanger; (c) Bergen; (d) Heimsjø; (e) Tromsø; and (f) Honningsvåg. The vertical bars on the right side of the panels represent the ensemble mean and ensemble spread (5\% to 95\%) for RSL change for 2081-2100. Annual mean tide gauge observations are shown in yellow.

The reasons for this become apparent when we examine the contributions from rapid ice dynamics in Antarctica, the steric/dyn signal and vertical land motion (Figure 8). These are the largest contributions to projected RSL change in Norway and, in general, the contributions with the largest uncertainties. Firstly, we note the rapid ice dynamic contribution from Antarctica is the same for all RCPs (i.e., it is RCP independent). IPCC AR5 assess that the scientific community is currently unable to quantify how Antarctic rapid ice dynamics relate to emission scenario, but such a dependency is expected to exist (see also Discussion). Secondly, we see that there is considerable overlap between the steric/dyn uncertainties for the different RCPs owing to the relatively large ensemble spread. For the period 1986-2005 to 2081-2100 the ensemble spread (5\% to 95\%) for the steric/dyn contribution is projected to be 0.05 to $0.35 \mathrm{~m}$ for RCP2.6; 0.13 to $0.43 \mathrm{~m}$ for RCP4.5; and 0.25 to 0.63 for RCP8.5. 
These values are for the average projected change across the Norwegian coastal municipalities. Thirdly, the contribution from vertical land motion is based upon the extrapolation of observed rates from the permanent GPS stations and levelling lines. This contribution is, therefore, clearly not related to present-day climate change and is also RCP independent.

Figure 11 shows the projected rates of sea-level change, these show considerable variability owing to interannual to decadal variability in the steric/dyn component (due to changes in heat uptake and wind stress simulated by the AOGCMs). For 2081-2100, we find that projected mean rates for RCP2.6 and RCP4.5 are broadly similar, whereas, for RCP8.5, ensemble mean rates are higher for the same period and the ensemble spread shows that rates may exceed $10 \mathrm{~mm} /$ year.
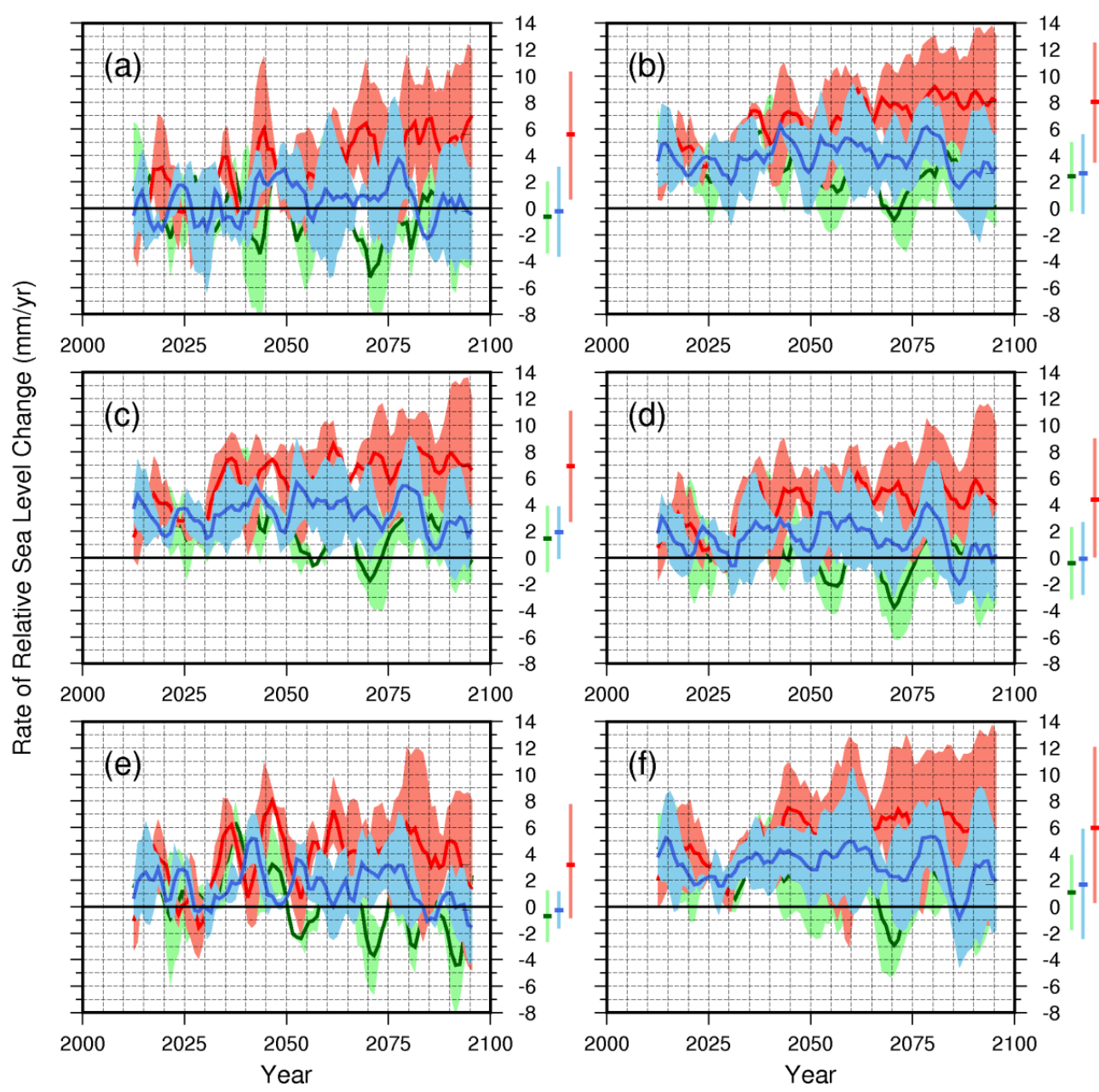

Figure 11. Projected rates of sea-level change for RCP2.6 (green), RCP4.5 (blue) and RCP8.5 (red) for the six key locations: (a) Oslo; (b) Stavanger; (c) Bergen; (d) Heimsjø; (e) Tromsø; and (f) Honningsvåg. Rates are calculated as linear trends over a 10-year moving window, the x-axis represents the mid-point of each window. The vertical bars on the right side of the panels represent the ensemble mean and ensemble spread ( $5 \%$ to $95 \%$ ) for rates calculated for the period 2081 to 2100.

\subsection{Combining Storm Surge Statistics with Sea-Level Projections}

\subsubsection{Changes in Return Heights and Return Periods with Sea-Level Rise}

Figure 12 shows changes in return heights after adding our twenty-first century mean relative sea-level projections. Changes in the likelihood of exceeding present-day return heights are dependent on both the projected sea-level change and the statistics of the observed sea level extremes (i.e., the 
spread between the different return heights, which determines the gradients of the lines shown in Figure 12) (see also Kopp et al. [19]). For Oslo, which has a relatively small projected sea-level change but has relatively large differences between the return heights, we expect only small changes in the frequency of exceedance (Figure 12a). However, for Stavanger and Bergen, the reverse is true and we therefore expect a large increase in the frequency of exceedance (Figure 12b,c).
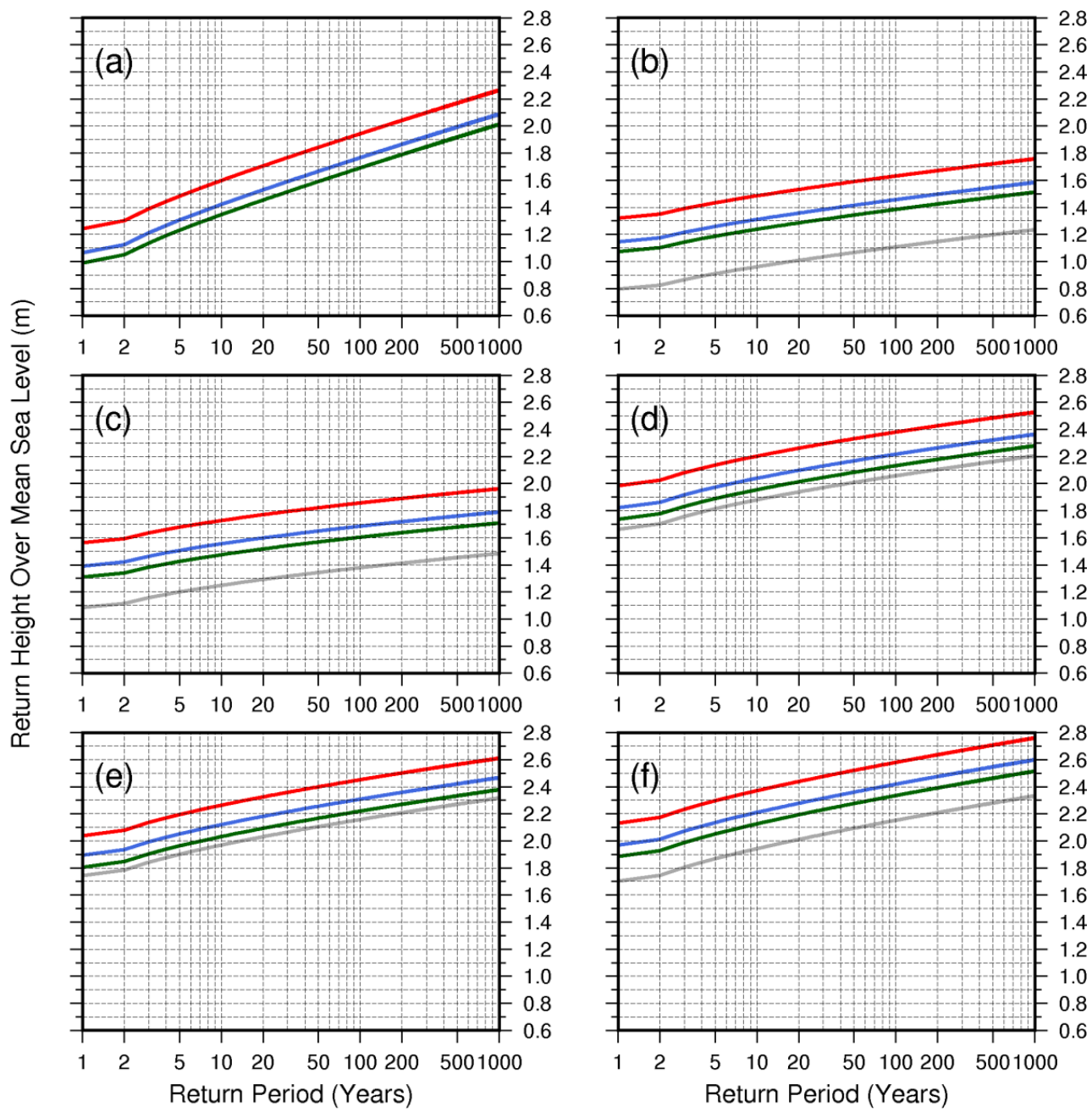

Figure 12. Return heights for stationary sea level (grey) and for ensemble mean RSL projections over the period 1986-2005 to 2081-2100 for RCP2.6 (green), RCP4.5 (blue) and RCP8.5 (red) at the six key locations: (a) Oslo; (b) Stavanger; (c) Bergen; (d) Heimsjø; (e) Tromsø; and (f) Honningsvåg. Note that the grey and blue lines coincide for Oslo.

An extreme sea level with a return period of 200 years will on average occur once every 200 years or, equivalently, has a $0.5 \%$ probability of occurring any given year. Figure 13 shows how the likelihood of exceeding the present 200-year return height can be dramatically increased with sea-level rise. By 2050, and only examining the ensemble mean projections, we see that the probability of exceeding the present 200-year return height will be $\sim 10 \%$ (or a 1 in 10 year event) in some areas. By the end of the 21st century, the 200-year return heights could be exceeded at least every year.

This is not a surprising result. For example, in Bergen, the 200-year return height lies $\sim 1.4 \mathrm{~m}$ above present mean sea level (grey line in Figure 12c). An extreme sea level of this height will cause nuisance flooding in the historic harbour area of the city. The ensemble mean projection for RCP4.5 indicates an RSL increase of $~ 0.3 \mathrm{~m}$ over 1986-2005 to 2081-2100 (blue line in Figure 12c). For this projection, therefore, we see that extreme sea levels reaching a height $1.4 \mathrm{~m}$ above present mean sea level will 
have a one-year return period by the end of the 21st century. For larger increases in RSL, we clearly expect flooding to occur more frequently, multiple times every year. In Bergen, the difference in height between the 200-year return period and the highest astronomical tide is $\sim 0.5 \mathrm{~m}$, i.e., with a RSL rise larger than this, then flooding at the level of the present 200-year return height will start to occur as part of the tidal regime.

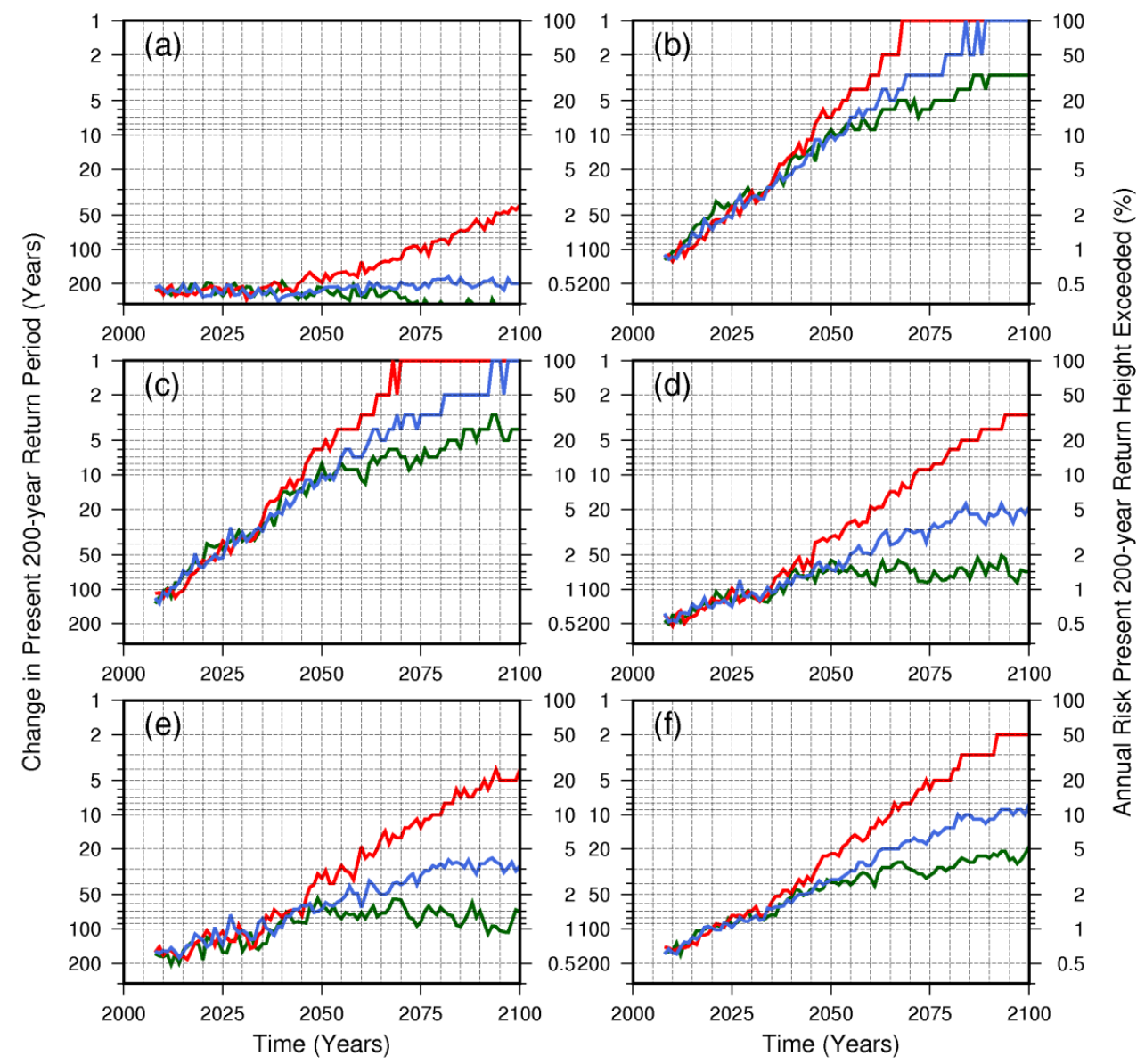

Figure 13. Changes in the 200-year return period (or risk) for the ensemble mean RSL projection for RCP2.6 (green), RCP4.5 (blue) and RCP8.5 (red) and at the locations: (a) Oslo; (b) Stavanger; (c) Bergen; (d) Heimsjø; (e) Tromsø; and (f) Honningsvåg.

\subsubsection{Sea Level Allowances}

Using our regional sea-level projections and ACER parameters for each tidal zone, we obtain allowances for the coastal municipalities in Norway (Tables 3-5 and Figures 14 and 15). A disadvantage of using the ACER method in this respect (as opposed to the Gumbel method; see Hunter [16] and Hunter et al. [17]) is that our allowances are dependent on the return height of interest. However, comparison of Tables 3-5 shows that differences due to changes in return height are generally no larger than $10 \mathrm{~cm}$. 
Table 3. Allowances (in cm) calculated for six key locations using the 20-year return heights and projected ensemble mean RSL change over the period 1986-2005 to 2081-2100 (the 5\% to 95\% ensemble spread is given in parentheses). Allowances are given for two different choices of the level of likelihood assigned to the ensemble spread. The parentheses next to the allowances give the value of the standard error above the ensemble mean projected RSL.

\begin{tabular}{|c|c|c|c|c|c|c|c|c|c|}
\hline Location & $\begin{array}{c}\text { RCP2.6 } \\
2081-2100\end{array}$ & $\begin{array}{c}\text { RCP2.6 } \\
\text { Allowance } \\
5-95 \%\end{array}$ & $\begin{array}{c}\text { RCP2.6 } \\
\text { Allowance } \\
17-83 \%\end{array}$ & $\begin{array}{c}\mathrm{RCP} 4.5 \\
2081-2100\end{array}$ & $\begin{array}{c}\text { RCP4.5 } \\
\text { Allowance } \\
5-95 \%\end{array}$ & $\begin{array}{c}\text { RCP4.5 } \\
\text { Allowance } \\
17-83 \%\end{array}$ & $\begin{array}{c}\text { RCP8.5 } \\
2081-2100\end{array}$ & $\begin{array}{c}\text { RCP8.5 } \\
\text { Allowance } \\
5-95 \%\end{array}$ & $\begin{array}{c}\text { RCP8.5 } \\
\text { Allowance } \\
17-83 \%\end{array}$ \\
\hline Oslo & $-7(-32$ to 16$)$ & $-1(7)$ & $12(17)$ & $0(-25$ to 24$)$ & $7(15)$ & $21(25)$ & $\begin{array}{c}18(-12 \text { to } \\
47)\end{array}$ & $28(36)$ & $45(48)$ \\
\hline Stavanger & 28 (5 to 50$)$ & $40(41)$ & $60(51)$ & 35 (12 to 58$)$ & $48(49)$ & $69(59)$ & 52 (25 to 79$)$ & $70(68)$ & $96(80)$ \\
\hline Bergen & 23 (3 to 42 ) & $32(35)$ & $48(43)$ & $31(10$ to 51$)$ & $41(43)$ & $59(52)$ & 48 (23 to 72$)$ & $62(63)$ & $85(73)$ \\
\hline Heimsjø & $7(-17$ to 27$)$ & $15(19)$ & $29(28)$ & $16(-5$ to 37$)$ & $25(29)$ & $40(38)$ & 30 (8 to 57$)$ & $45(46)$ & $65(58)$ \\
\hline Tromsø & $6(-10$ to 23$)$ & $12(16)$ & $22(24)$ & $15(-3$ to 34$)$ & $22(27)$ & $34(35)$ & $29(5$ to 55$)$ & $42(45)$ & $63(56)$ \\
\hline Honningsvåg & $18(-7$ to 44$)$ & $30(34)$ & $50(45)$ & 27 (0 to 53) & 39 (43) & $61(54)$ & $43(10$ to 76$)$ & $62(63)$ & $93(77)$ \\
\hline
\end{tabular}

Table 4. Allowances (in cm) calculated for six key locations using the 200-year return heights and projected ensemble mean RSL change over the period 1986-2005 to 2081-2100 (the 5\% to 95\% ensemble spread is given in parentheses). Allowances are given for two different choices of the level of likelihood assigned to the ensemble spread. The parentheses next to the allowances give the value of the standard error above the ensemble mean projected RSL.

\begin{tabular}{|c|c|c|c|c|c|c|c|c|c|}
\hline Location & $\begin{array}{c}\text { RCP2.6 } \\
2081-2100\end{array}$ & $\begin{array}{c}\text { RCP2.6 } \\
\text { Allowance } \\
5-95 \%\end{array}$ & $\begin{array}{c}\text { RCP2.6 } \\
\text { Allowance } \\
17-83 \%\end{array}$ & $\begin{array}{c}\text { RCP4.5 } \\
2081-2100\end{array}$ & $\begin{array}{c}\mathrm{RCP} 4.5 \\
\text { Allowance } \\
5-95 \%\end{array}$ & $\begin{array}{c}\text { RCP4.5 } \\
\text { Allowance } \\
\text { 17-83\% }\end{array}$ & $\begin{array}{c}\text { RCP8.5 } \\
2081-2100\end{array}$ & $\begin{array}{c}\text { RCP8.5 } \\
\text { Allowance } \\
5-95 \%\end{array}$ & $\begin{array}{c}\text { RCP8.5 } \\
\text { Allowance } \\
17-83 \%\end{array}$ \\
\hline Oslo & $-7(-32$ to 16$)$ & $0(7)$ & $14(17)$ & 0 (-25 to 24$)$ & $8(15)$ & $22(25)$ & $\begin{array}{c}18(-12 \text { to } \\
47)\end{array}$ & $28(36)$ & $47(48)$ \\
\hline Stavanger & 28 (5 to 50$)$ & $42(41)$ & $65(51)$ & 35 (12 to 58$)$ & $50(49)$ & $75(59)$ & 52 (25 to 79$)$ & $72(68)$ & $104(80)$ \\
\hline Bergen & 23 (3 to 42 ) & $35(35)$ & $54(43)$ & 31 (10 to 51$)$ & $44(43)$ & $65(52)$ & 48 (23 to 72$)$ & $66(63)$ & $93(73)$ \\
\hline Heimsjø & $7(-17$ to 27$)$ & $17(19)$ & $34(28)$ & $16(-5$ to 37$)$ & $27(29)$ & $45(38)$ & 30 (8 to 57$)$ & $47(46)$ & $72(58)$ \\
\hline Tromsø & $6(-10$ to 23$)$ & $13(16)$ & $25(24)$ & $15(-3$ to 34$)$ & $23(27)$ & $38(35)$ & 29 (5 to 55$)$ & $45(45)$ & $70(56)$ \\
\hline Honningsvåg & $18(-7$ to 44$)$ & $32(34)$ & $56(45)$ & $27(0$ to 53$)$ & $42(43)$ & $67(54)$ & 43 (10 to 76$)$ & $66(63)$ & $102(77)$ \\
\hline
\end{tabular}


Table 5. Allowances (in cm) calculated for six key locations using the 1000-year return heights and projected ensemble mean RSL change over the period 1986-2005 to 2081-2100 (the 5\% to 95\% ensemble spread is given in parentheses). Allowances are given for two different choices of the level of likelihood assigned to the ensemble spread. The parentheses next to the allowances give the value of the standard error above the ensemble mean projected RSL.

\begin{tabular}{|c|c|c|c|c|c|c|c|c|c|}
\hline Location & $\begin{array}{c}\mathrm{RCP} 2.6 \\
2081-2100\end{array}$ & $\begin{array}{c}\text { RCP2.6 Allowance } \\
5-95 \%\end{array}$ & $\begin{array}{c}\text { RCP2.6 } \\
\text { Allowance } \\
17-83 \%\end{array}$ & $\begin{array}{c}\mathrm{RCP} 4.5 \\
2081-2100\end{array}$ & $\begin{array}{c}\text { RCP4.5 } \\
\text { Allowance } \\
5-95 \%\end{array}$ & $\begin{array}{c}\text { RCP4.5 } \\
\text { Allowance } \\
17-83 \%\end{array}$ & $\begin{array}{c}\mathrm{RCP} 8.5 \\
2081-2100\end{array}$ & $\begin{array}{c}\text { RCP8.5 } \\
\text { Allowance } \\
5-95 \%\end{array}$ & $\begin{array}{c}\text { RCP8.5 } \\
\text { Allowance } \\
17-83 \%\end{array}$ \\
\hline Oslo & $-7(-32$ to 16$)$ & $0(7)$ & $14(17)$ & $0(-25$ to 24$)$ & $8(15)$ & $23(25)$ & $18(-12$ to 47$)$ & $29(36)$ & $48(48)$ \\
\hline Stavanger & 28 (5 to 50$)$ & $43(41)$ & $69(51)$ & $35(12$ to 58$)$ & $51(49)$ & 79 (59) & $52(25$ to 79$)$ & $74(68)$ & $109(80)$ \\
\hline Bergen & 23 (3 to 42$)$ & $36(35)$ & $58(43)$ & $31(10$ to 51$)$ & $46(43)$ & $70(52)$ & $48(23$ to 72$)$ & $68(63)$ & $97(73)$ \\
\hline Heimsjø & 7 (-17 to 27$)$ & $18(19)$ & $37(28)$ & $16(-5$ to 37$)$ & $28(29)$ & $48(38)$ & $30(8$ to 57$)$ & 49 (46) & $77(58)$ \\
\hline Tromsø & $6(-10$ to 23$)$ & $14(16)$ & $27(24)$ & $15(-3$ to 34$)$ & $24(27)$ & $41(35)$ & $29(5$ to 55$)$ & $46(45)$ & $75(56)$ \\
\hline Honningsvåg & $18(-7$ to 44$)$ & $33(34)$ & $59(45)$ & $27(0$ to 53$)$ & $43(43)$ & $71(54)$ & $43(10$ to 76$)$ & $68(63)$ & $108(77)$ \\
\hline
\end{tabular}



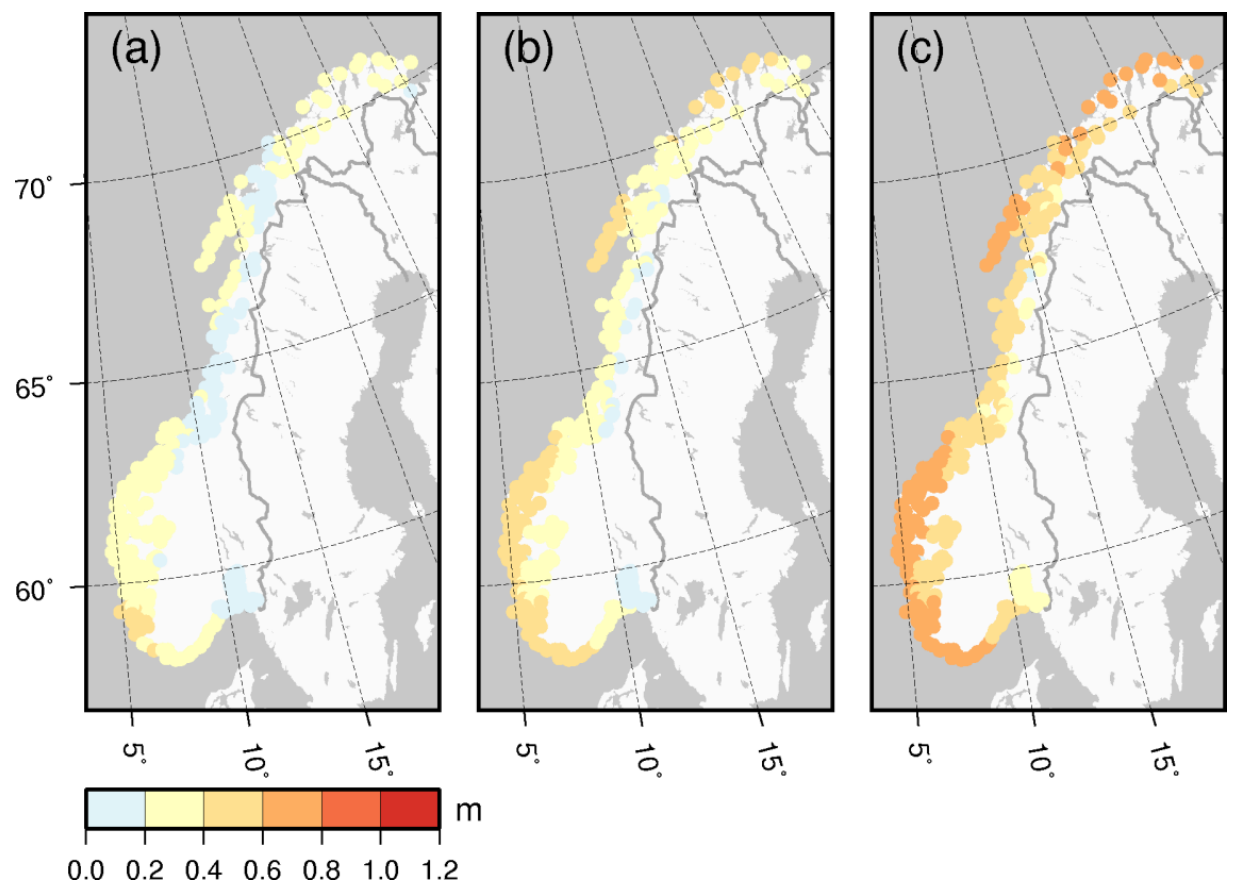

Figure 14. Allowances (m) for the 290 coastal municipalities in Norway calculated using the 200-year return heights and projected RSL change over the period 1986-2005 to 2081-2100 for: (a) RCP2.6; (b) RCP4.5; and (c) RCP8.5. We assume that the model range corresponds to the $5 \%$ to $95 \%$ probability bounds and fit a normal distribution.
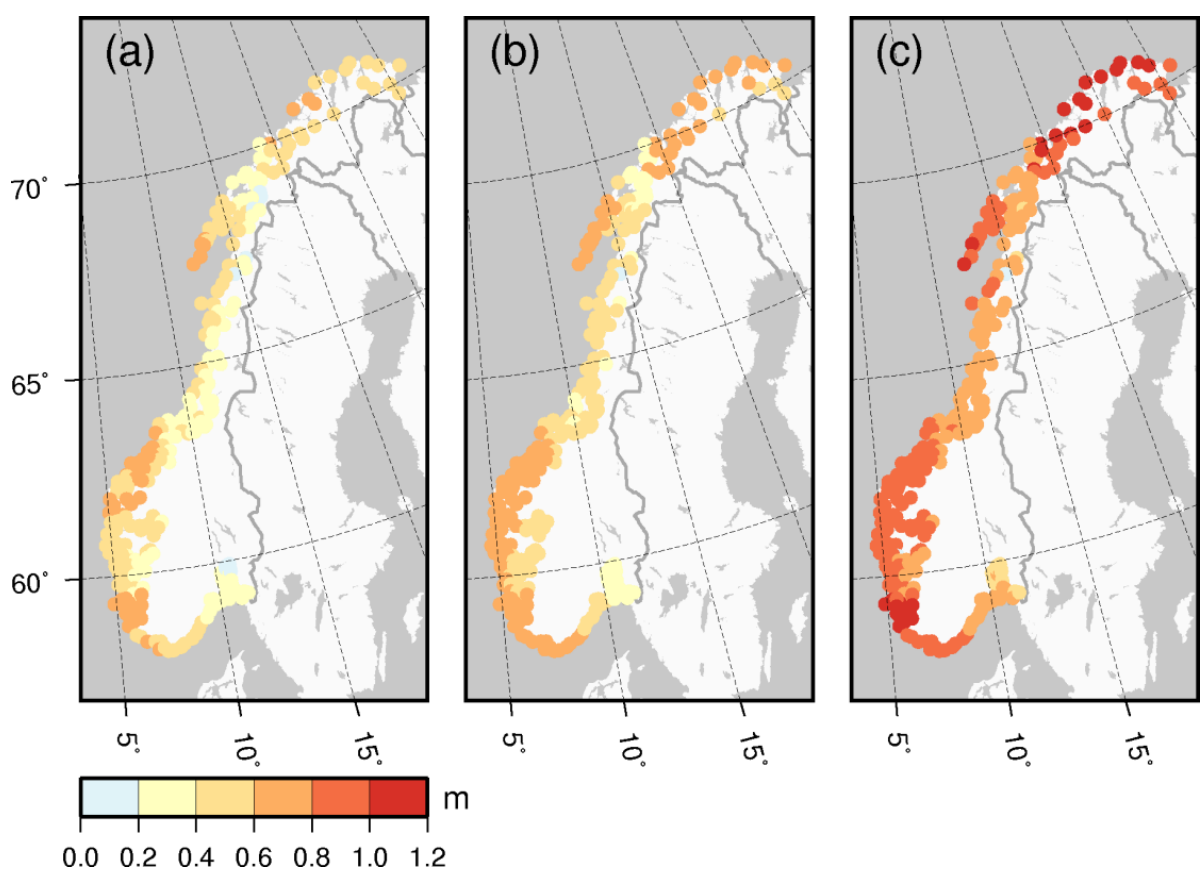

Figure 15. Allowances (m) for the 290 coastal municipalities in Norway calculated using the 200-year return heights and projected RSL change over the period 1986-2005 to 2081-2100 for: (a) RCP2.6; (b) RCP4.5; and (c) RCP8.5. We assume that the model range corresponds to the $17 \%$ to $83 \%$ probability bounds and fit a normal distribution. 
Allowances are calculated in two alternative ways using a normal distribution: (1) assuming that the model spread does in fact correspond to the $5 \%$ and $95 \%$ probability bounds (e.g., $[62,63]$ ) and (2) assuming that the model spread being defined as the likely range in IPCC AR5 ( $p>66 \%)$ corresponds to the $17 \%$ and $83 \%$ probability bounds. Note that the latter is one interpretation of the likely range. The use of likely in IPCC AR5 means that there is a probability of $33 \%$ or less that future sea level will lie outside the model spread (and that $33 \%$ is not necessarily symmetrically distributed) [14]. The difference between the two sets of allowances calculated here, therefore, is simply the difference in the spread of the sea-level projections. For allowances computed using the model spread as the 5\% to $95 \%$ probability bounds, then the allowance generally lies around the mark of the standard error above the mean, but below the top of the IPCC AR5 likely range (see also Hunter et al. [17]), whereas, when calculating allowances using the model range as the $17 \%$ to $83 \%$ probability bounds, then the allowances generally lie above the mark of the standard error above the mean, and also above the top of the IPCC AR5 likely range (Tables 3-5). The allowances are therefore quite sensitive to the assumed spread of the probability distribution of future sea-level rise. Note that all allowances calculated give values above the ensemble mean, i.e., to preserve the likelihood of flooding from extreme sea levels, a height increase above the most likely RSL rise should be used in planning. The pattern of allowance heights (Figures 14 and 15) reflects spatial differences in both the RSL projections and statistics of the extreme sea levels.

\section{Discussion}

Projecting future sea-level change is a challenging task as it requires a sound understanding of many different aspects of the Earth-climate system. Key to improving our understanding of sea level is being able to identify the separate contributions to regional sea-level change. For Norway, part of achieving that goal means maintaining and improving the national sea level observing system (the tide gauge network and geodetic observation used to constrain land motion).

Our regional sea-level projections are based on findings from IPCC AR5 and CMIP5 model output. The projections take into account spatial variations in: (1) ocean density, ocean mass redistribution, and dynamics; (2) ocean mass changes and associated gravitational effects on sea level; and (3) vertical land motion and associated gravitational effects on sea level. We pay special attention to land motion due to GIA, which is better constrained using new GPS [2] and levelling observations. The generally good fit between the GPS data and GIA modelling results gives us confidence that the observations can be extrapolated into the future. Our full GIA solution, as a contribution to RSL change, is the VLM field determined from least-squares collocation (e.g., [33]) added to modelled gravitational effects on sea level associated with GIA.

Projected ensemble mean 21st century RSL changes in Norway are, depending on location, from -0.10 to $0.30 \mathrm{~m}$ for RCP2.6; 0.00 to $0.35 \mathrm{~m}$ for RCP 4.5 ; and 0.15 to $0.55 \mathrm{~m}$ for RCP8.5. The projections show, unsurprisingly, that the pattern of twenty-first century RSL changes for Norway is governed by GIA. For all RCPs, projected ensemble mean changes indicate that the majority of Norway will experience a RSL rise over the period 1986-2005 to 2081-2100. Thus, climate driven sea-level rise will dominate over VLM over the next 100 years. This represents a reversal of the late-Holocene trend of RSL fall (see e.g., [6]). By the end of the 21st century, the ensemble spread shows rates of RSL rise may approach or exceed $\sim 10 \mathrm{~mm}$ /year for RCP8.5.

The projections presented here are given with corresponding $5 \%$ to $95 \%$ model ranges which are defined as the likely range in IPCC AR5 ( $p>66 \%$ ). Quantifying the probability of levels above the likely range (i.e., the upper tail of the probability distribution) remains difficult because information is lacking [14]. Of particular concern is the ice sheet contribution, which potentially could be quite large, especially if a collapse of the marine portions of the Antarctic ice sheet were to be triggered (see Alley et al. [64] for a review). As mentioned, recent modelling studies of Antarctica have tried to quantify how such a marine collapse might contribute to future sea-level rise from the continent with diverging results (e.g., [22,23]). We note that the modelling study by Ritz et al. [22] is broadly in line 
with IPCC AR5, and indicates a complex and skewed distribution of future ice loss from Antarctica, whereas DeConto and Pollard [23] show by incorporating new processes-the hydrofracturing of buttressing ice shelves and the collapse of ice cliffs-future ice mass loss from Antarctica is strongly RCP dependent and that the ice sheet has the potential to contribute more than a metre of sea-level rise by 2100 . This would suggest that projections based on IPCC AR 5 science are systematically biased low, however, we caution that this is the result from only one study.

Regional sea-level change beyond 2100 is not dealt with in this paper. However, it is clear sea level will continue to rise after this time owing to the long response times of the oceans and ice sheets (e.g., [65]). Evidence from the paleo record shows that, with even moderate warming, that is, temperatures close to those we observe today, the Greenland and Antarctic ice sheets contributed to a multi-meter sea-level rise above present-day levels [66].

Return heights for extreme sea levels are calculated using statistical analysis (the ACER method) of observations from the Norwegian tide gauge network. Return heights for other points along the coast are found by analysing extrapolated observations where temporary tide gauges are used to quantify the relationship between the tidal behaviour of the temporary and permanent tide gauges. In this work we have assumed no future changes to the amplitude or frequency of the extremes. (However, as shown, sea level extremes and their associated risks will nevertheless increase with mean sea-level rise). Changes in extreme sea levels can arise due to changes in storminess and/or the wave climate and wave setup. Examining evidence on this from an earlier study of the tide gauge records, we find that the picture is somewhat mixed. Some Norwegian tide gauges indicate a small but statistically significant positive late 20th century trend in storm surge heights when compared to the mean sea-level change, while others indicate a negative or insignificant trend [67]. Projections of wind and wave climate, relevant indicators for changes in storm surges, show in general little expected change in our regions. Sterl et al. [68] forced a storm surge model with wind data from an ensemble of 17 climate model runs for 1950-2100. The authors found no significant change in the direction of strong winds (near gale winds or more) in southern and western Norway over this period. Debernard and Røed [69] performed a similar study based on the moderate IPCC scenarios and projected a weak $(2-6 \%)$ increase in storm surges along the Norwegian coast. However, the authors also point out that storm surge events are extremely dependent on the local conditions (topography and the movement of the storms). Other model studies project little change in wave climate, however, the same studies also caution that confidence in projections of waves and storm surges is very low (e.g., [70]).

Using our regional sea-level projections and ACER parameters for each tidal zone, we have calculated allowances for the 290 coastal municipalities in Norway. We have made some tests of the method by assuming that our regional sea-level projections are normally distributed. If the distribution were skewed, however, this would presumably result in higher allowances than those presented here [71]. A disadvantage of using the ACER method (as opposed to the Gumbel method) is that our allowances are dependent on the return height of interest. All the allowances calculated give values above the projected ensemble mean RSL rise, i.e., to preserve the likelihood of flooding from extreme sea levels, a height increase above the most likely RSL rise should be used in planning. Finally, we note that changes in the likelihood of flooding are dependent on both the projected sea-level change and the statistics of the observed extreme sea levels. The likelihood of exceeding present-day return heights can be dramatically increased with sea-level rise.

Acknowledgments: The work was commissioned and partly funded by the Norwegian Environment Agency. Support was also provided by the Centre for Climate Dynamics at the Bjerknes Centre, through the project iNcREASE.

Author Contributions: M.J.R.S. and J.E.Ø.N. conceived and designed the experiments; M.J.R.S., O.R.R., H.S., O.V. and H.S. performed the experiments and analysed the data; J.E.Ø.N. and H.P.K. contributed materials; and all authors contributed to writing the paper.

Conflicts of Interest: The authors declare no conflict of interest. 


\section{References}

1. Milne, G.A.; Davis, J.L.; Mitrovica, J.X.; Scherneck, H.-G.; Johansson, J.M.; Vermeer, M.; Koivula, H. Space-geodetic constraints on glacial isostatic adjustment in Fennoscandia. Science 2001, 291, 2381-2385. [CrossRef] [PubMed]

2. Kierulf, H.P.; Steffen, H.; Simpson, M.J.R.; Lidberg, M.; Wu, P.; Wang, H. A GPS velocity field for Fennoscandia and a consistent comparison to glacial isostatic adjustment models. J. Geophys. Res. Solid Earth 2014, 119. [CrossRef]

3. Simpson, M.; Breili, K.; Kierulf, H.P. Estimates of twenty-first century sea-level changes for Norway. Clim. Dyn. 2014, 42, 6613-6629. [CrossRef]

4. Aunan, K.; Romstad, B. Strong coasts and vulnerable communities: Potential implications of accelerated sea-level rise for Norway. J. Coast. Res. 2008, 24, 403-409. [CrossRef]

5. Anders, A.J.; Hygen, H.O. Impacts of sea level rise towards 2100 on buildings in Norway. Build. Res. Inf. 2012, 40, 245-259.

6. Lambeck, K.; Smither, C.; Johnston, P. Sea-level change, glacial rebound and mantle viscosity for northern Europe. Geophys. J. Int. 1998, 134, 102-144. [CrossRef]

7. Ekman, M. A consistent map of the post glacial uplift of Fennoscandia. Terra Nova 1996, 8, 158-165. [CrossRef]

8. Henry, O.; Prandi, P.; Llovel, W.; Cazenave, A.; Jevrejeva, S.; Stammer, D.; Meyssignac, B.; Koldunov, N. Tide gauge-based sea level variations since 1950 along the Norwegian and Russian coasts of the Arctic Ocean: Contribution of the steric and mass components. J. Geophys. Res. 2012, 117. [CrossRef]

9. Richter, K.; Nilsen, J.E.Ø.; Drange, H. Contributions to sea level variability along the Norwegian coast for 1960-2010. J. Geophys. Res. 2012, 117. [CrossRef]

10. Breili, K.; Simpson, M.J.R.; Nilsen, J.E.Ø. Observed sea-level changes along the Norwegian coast. J. Mar. Sci. Eng. 2017, 5, 29. [CrossRef]

11. Church, J.A.; Clark, P.U.; Cazenave, A.; Gregory, J.M.; Jevrejeva, S.; Levermann, A.; Merrifield, M.A.; Milne, G.A.; Nerem, R.S.; Nunn, P.D.; et al. Sea level change. In Climate Change 2013: The Physical Science Basis. Contribution of Working Group I to the Fifth Assessment Report of the Intergovernmental Panel on Climate Change; Stocker, T.F., Qin, D., Plattner, G.-K., Tignor, M., Allen, S.K., Boschung, J., Nauels, A., Xia, Y., Bex, V., Midgley, P.M., Eds.; Cambridge University Press: Cambridge, UK; New York, NY, USA, 2013.

12. Gregory, J.M.; White, N.J.; Church, J.A.; Bierkens, M.F.P.; Box, J.E.; van den Broeke, M.R.; Cogley, J.G.; Fettweis, X.; Hanna, E.; Huybrechts, P.; et al. Twentieth-century global-mean sea-level rise: Is the whole greater than the sum of the parts? J. Clim. 2012, 26. [CrossRef]

13. Nick, F.M.; Vieli, A.; Andersen, M.L.; Joughin, I.; Payne, A.; Edwards, T.L.; Pattyn, F.; van de Wal, R.S. Future sea-level rise from Greenland's major outlet glaciers in a warming climate. Nature 2013, 497, 235-238. [CrossRef] [PubMed]

14. Clark, P.U.; Church, J.A.; Gregory, J.M.; Payne, A.J. Recent progress in understanding and projecting regional and global mean sea level change. Curr. Clim. Chang. Rep. 2015, 1, 224-246. [CrossRef]

15. Hinkel, J.; Jaeger, C.; Nicholls, R.J.; Lowe, J.; Renn, O.; Peijun, S. Sea-level rise scenarios and coastal risk management. Nat. Clim. Chang. 2015, 5, 188-190. [CrossRef]

16. Hunter, J. A simple technique for estimating an allowance for uncertain sea-level rise. Clim. Chang. 2012, 113, 239-252. [CrossRef]

17. Hunter, J.R.; Church, J.A.; White, N.J.; Zhang, X. Towards a global regionally varying allowance for sea-level rise. Ocean Eng. 2013, 71, 17-27. [CrossRef]

18. Jevrejeva, S.; Grinsted, A.; Moore, J.C. Upper limit for sea level projections by 2100. Environ. Res. Lett. 2014, 9, 104008. [CrossRef]

19. Kopp, R.E.; Horton, R.M.; Little, C.M.; Mitrovica, J.X.; Oppenheimer, M.; Rasmussen, D.J.; Strauss, B.H.; Tebaldi, C. Probabilistic 21st and 22nd century sea-level projections at a global network of tide-gauge sites. Earth's Future 2014, 2, 383-406. [CrossRef]

20. Joughin, I.; Smith, B.E.; Medley, B. Marine ice sheet collapse potentially under way for the Thwaites Glacier Basin, West Antarctica. Science 2014, 244. [CrossRef] [PubMed]

21. Rignot, E.; Mouginot, J.; Morlighem, M.; Seroussi, H.; Scheuchl, B. Widespread, rapid grounding line retreat of Pine Island, Thwaites, Smith, and Kohler glaciers, West Antarctica, from 1992 to 2011. Geophys. Res. Lett. 2014, 41, 3502-3509. [CrossRef] 
22. Ritz, C.; Edwards, T.L.; Durand, G.; Payne, A.J.; Peyaud, V.; Hindmarsh, R.C.A. Potential sea-level rise from Antarctic ice-sheet instability constrained by observations. Nature 2015, 528, 115-118. [CrossRef] [PubMed]

23. Deconto, R.M.; Pollard, D. Contribution of Antarctica to past and future sea-level rise. Nature 2016, 531, 591-597. [CrossRef] [PubMed]

24. Taylor, K.; Stouer, R.J.; Meehl, G.A. An overview of CMIP5 and the experiment design. Bull. Am. Meteorol. Soc. 2012, 93, 485498. [CrossRef]

25. Ravndal, O.R.; Sande, B.H. Ekstremverdianalyse av Vannstandsdata Langs Norskekysten; Technical Report NDDF 16-1; Norwegian Mapping Authority, Hydrographic Service: Stavanger, Norway, January 2016; p. 26.

26. Ekman, M. A concise history of post glacial land uplift research (from its beginning to 1950). Terra Nova 1991, 3, 358-365. [CrossRef]

27. Steffen, H.; Wu, P. Glacial isostatic adjustment in Fennoscandia-A review of data and modeling. J. Geodyn. 2011, 52, 160-2004. [CrossRef]

28. Milne, G.A.; Mitrovica, J.X.; Scherneck, H.G.; Davis, J.L.; Johansson, J.M. Continuous GPS measurements of postglacial adjustment in Fennoscandia: 2 modeling results. J. Geophys. Res. 2004, 109. [CrossRef]

29. Steffen, H.; Kaufmann, G. Glacial isostatic adjustment of Scandinavia and northwestern Europe and the radial viscosity structure of the Earth's mantle. Geophys. J. Int. 2005, 163, 801-812. [CrossRef]

30. Olesen, O.; Kierulf, H.P.; Brönner, M.; Dalsegg, E.; Fredin, O.; Solbakk, T. Deep weathering, neotectonics and strandflat formation in Nordland, northern Norway. Nor. J. Geol. 2013, 93, 189-213.

31. Steffen, H.; Gitlein, O.; Denker, H.; Müller, J.; Timmen, L. Present rate of uplift in Fennoscandia from GRACE and absolute gravimetry. Tectonophysics 2009, 474, 69-77. [CrossRef]

32. Ekman, M.; Mäkinen, J. Recent post glacial rebound, gravity change and mantle flow in Fennoscandia. Geophys. J. Int. 1996, 126, 229-234. [CrossRef]

33. Vestøl, O. Determination of postglacial land uplift in Fennoscandia from leveling, tide-gauges and continuous GPS stations using least squares collocation. J. Geod. 2006, 80, 248-258. [CrossRef]

34. Peltier, W.R. Global glacial isostasy and the surface of the ice-age earth: The ICE-5G (VM2) model and GRACE. Annu. Rev. Earth Planet. Sci. 2004, 32, 111-149. [CrossRef]

35. Scherneck, H.-G.; Johansson, J.M.; Mitrovica, J.X.; Davis, J.L. The BIFROST project: GPS determined 3-D displacement rates in Fennoscandia from 800 days of continuous observations in the SWEPOS network. Tectonophysics 1998, 294, 305-321. [CrossRef]

36. Johansson, J.M.; Davis, J.L.; Scherneck, H.G.; Milne, G.A.; Vermeer, M.; Mitrovica, J.X.; Bennett, R.A.; Jonsson, B.; Elgered, G.; Elósegui, P.; et al. Continous GPS measurements of postglacial adjustment in Fennoscandia 1 Geodetic result. J. Geophys. Res. 2002, 107, 2157. [CrossRef]

37. Lidberg, M.; Johansson, J.; Scherneck, H.G.; Davis, J. An improved and extended GPS-derived velocity field for the glacial isostatic adjustment in Fennoscandia. J. Geod. 2007, 81, 213-230. [CrossRef]

38. Lidberg, M.; Johansson, J.M.; Scherneck, H.G.; Milne, G.A. Recent results based on continuous GPS observations of the GIA process in Fennoscandia from BIFROST. J. Geodyn. 2010, 50, 8-18. [CrossRef]

39. Kierulf, H.P.; Ouassou, M.; Simpson, M.J.R.; Vestøl, O. A continuous velocity field for Norway. J. Geod. 2012, 87, 337-349. [CrossRef]

40. Herring, T.; King, R.; McClusky, S. Introduction to GAMIT/GLOBK Release 10.4; Technical Report; Massachusetts Institute of Technology: Cambridge, MA, USA, 2011.

41. Altamimi, Z.; Collilieux, X.; Metivier, L. ITRF2008: An improved solution of the international terrestrial reference frame. J. Geod. 2011, 85, 457-473. [CrossRef]

42. Collilieux, X. External evaluation of the terrestrial reference frame: Report of the taskforce of the IAG sub-commission 1.2. In Earth on the Edge: Science for a Sustainable Planet; Rizos, C., Willis, P., Eds.; Springer: Berlin/Heidelberg, Germany, 2014; pp. 197-202.

43. Farrell, W.E.; Clark, J.A. On postglacial sea level. Geophys. J. R. Astron. Soc. 1976, 46, 647-667. [CrossRef]

44. Milne, G.A.; Mitrovica, J.X. Postglacial sea-level change on a rotating Earth. Geophys. J. Int. 1998, 133, 1-19. [CrossRef]

45. Kendall, R.; Latychev, K.; Mitrovica, J.X.; Davis, J.E.; Tamisiea, M. Decontaminating tide gauge records for the influence of Glacial Isostatic Adjustment: The potential impact of 3-D Earth structure. Geophys. Res. Lett. 2006, 33, L24318. [CrossRef]

46. Wu, P. Response of a Maxwell Earth to Applied Surface Mass Loads: Glacial Isostatic Adjustment. Master's Thesis, Department of Physics, University of Toronto, Toronto, ON, Canada, 1978. 
47. Dziewonski, A.M.; Anderson, D.L. Preliminary reference Earth model. Phys. Earth Planet. Inter. 1981, 25, 297-356. [CrossRef]

48. Tushingham, A.M.; Peltier, W.R. Ice-3G: A new global model of late Pleistocene deglaciation based upon geophysical predictions of post-glacial relative sea level change. J. Geophys. Res. 1991, 96, 4497-4523. [CrossRef]

49. Zhao, S.; Lambeck, K.; Lidberg, M. Lithosphere thickness and mantle viscosity inverted from GPS-derived deformation rates in Fennoscandia. Geophys. J. Int. 2012, 190, 278-292. [CrossRef]

50. Milne, G.A.; Gehrels, W.R.; Hughes, C.W.; Tamisiea, M.E. Identifying the causes for sea-level change. Nat. Geosci. 2009, 2, 471-478. [CrossRef]

51. Richter, K.; Riva, R.E.M.; Drange, H. Impact of self-attraction and loading effects induced by shelf mass loading on projected regional sea level rise. Geophys. Res. Lett. 2013, 40. [CrossRef]

52. Yin, J.; Griffies, S.M.; Stouffer, R.J. Spatial variability of sea-level rise in the twenty-first century projections. J. Clim. 2010, 23, 4585-4607. [CrossRef]

53. Haug, E. Extreme Value Analysis of Sea Level Observations; Technical Report DAF 12-1; Norwegian Mapping Authority, Hydrographic Service: Stavanger, Norway, January 2012; p. 180.

54. Skjong, M.; Næss, A.; Næss, O.E.B. Statistics of extreme sea levels for locations along the Norwegian coast. J. Coast. Res. 2013, 29, 1029-1048. [CrossRef]

55. Næss, A.; Gaidai, O. Estimation of extreme values from sampled time series. Struct. Saf. 2009, 31, 325-334. [CrossRef]

56. Tamisiea, M.E.; Mitrovica, J.X. The moving boundaries of sea level change: Understanding the origins of geographic variability. Oceanography 2011, 24, 24-39. [CrossRef]

57. Love, R.; Milne, G.A.; Tarasov, L.; Engelhart, S.E.; Hijma, M.P.; Latychev, K.; Horton, B.P.; Törnqvist, T.E. The contribution of glacial isostatic adjustment to projections of sea-level change along the Atlantic and Gulf coasts of North America. Earth's Future 2016, 4, 440-464. [CrossRef]

58. Yin, J. Century to multi-century sea level rise projections from CMIP5 models. Geophys. Res. Lett. 2012, 39, L17709. [CrossRef]

59. Landerer, F.W.; Jungclaus, J.H.; Marotzke, J. Regional dynamic and steric sea level change in response to the IPCC-A1B scenario. J. Phys. Oceanogr. 2007, 37, 296-312. [CrossRef]

60. Katsman, C.A.; Hazeleger, W.; Drijfhout, S.S.; van Oldenborgh, G.J.; Burgers, G. Climate scenarios of sea level rise for the northeast Atlantic Ocean: A study including the effects of ocean dynamics and gravity changes induced by ice melt. Clim. Chang. 2008. [CrossRef]

61. Pardaens, A.K.; Gregory, J.M.; Lowe, J.A. A model study of factors influencing projected changes in regional sea level over the twenty-first century. Clim. Dyn. 2011, 36, 2015-2033. [CrossRef]

62. McInnes, K.L.; Church, J.; Monselesan, D.; Hunter, J.; O'Grady, J.; Haigh, I.; Zhang, X. Information for Australian impact and adaptation planning in response to sea-level rise. Aust. Meteorol. Oceanogr. J. 2015, 65, 127-149. [CrossRef]

63. Zhai, L.; Greenan, B.J.; Hunter, J.; James, T.S.; Han, G.; MacAulay, P.; Henton, J.A. Estimating sea-level allowances for Atlantic Canada using the Fifth assessment report of the IPCC. Atmosphere-Ocean 2015, 53, 476-490. [CrossRef]

64. Alley, R.B.; Anandakrishnan, S.; Christianson, K.; Horgan, H.J.; Muto, A.; Parizek, B.R.; Pollard, D.; Walker, R.T. Oceanic forcing of ice-sheet retreat: West Antarctica and more. Ann. Rev. Earth Planet. Sci. 2015, 43, 207-231. [CrossRef]

65. Clark, P.U.; Shakun, J.D.; Marcott, S.A.; Mix, A.C.; Eby, M.; Kulp, S.; Levermann, A.; Milne, G.A.; Pfister, P.L.; Santer, B.D.; et al. Consequences of twenty-first-century policy for multi-millennial climate and sea-level change. Nat. Clim. Chang. 2016, 6, 360-369. [CrossRef]

66. Dutton, A.; Carlson, A.E.; Long, A.J.; Milne, G.A.; Clark, P.U.; DeConto, R.; Horton, B.P.; Rahmstorf, S.; Raymo, M.E. Sea-level rise due to polar ice-sheet mass loss during past warm periods. Science 2015, 349, 6244. [CrossRef] [PubMed]

67. Menéndez, M.; Woodworth, P.L. Changes in extreme high water levels based on a quasi-global tide-gauge data set. J. Geophys. Res. 2010, 115, C10011. [CrossRef]

68. Sterl, A.; van den Brink, H.W.; de Vries, H.; Haarsma, R.; van Meijgaard, E. An ensemble study of extreme North Sea storm surges in a changing climate. Ocean Sci. 2009, 5, 369-378. [CrossRef] 
69. Debernard, J.B.; Røed, L.P. Future wind, wave and storm surge climate in the Northern Seas: A revisit. Tellus A 2008, 60, 427-438. [CrossRef]

70. Hemer, M.A.; Fan, Y.; Mori, N.; Semedo, A.; Wang, X.L. Projected changes in wave climate from a multi-model ensemble. Nat. Clim. Chang. 2013. [CrossRef]

71. Slangen, A.B.A.; Roderik, S.W.W.; Reerink, T.J.; de Winter, R.C.; Hunter, J.R.; Woodworth, P.L.; Edwards, T. The impact of uncertainties in ice sheet dynamics on sea-level allowances at tide gauge locations. J. Mar. Sci. Eng. 2017, 5, 21. [CrossRef]

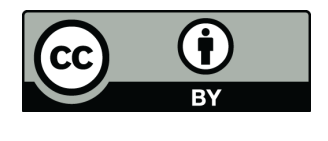

(c) 2017 by the authors. Licensee MDPI, Basel, Switzerland. This article is an open access article distributed under the terms and conditions of the Creative Commons Attribution (CC BY) license (http:/ / creativecommons.org/licenses/by/4.0/). 